\title{
An assessment of Saharan dust loading and the corresponding cloud-free longwave direct radiative effect from geostationary satellite observations
}

\author{
Helen E. Brindley ${ }^{1}$ and Jacqueline E. Russell ${ }^{1}$ \\ Received 16 December 2008; revised 24 July 2009; accepted 25 August 2009; published 5 December 2009.
}

[1] Previously, a method was developed to quantify Saharan dust optical thickness and simultaneously diagnose the cloud-free longwave dust direct radiative effect ( $\left.\mathrm{LW}_{\mathrm{DRE}}\right)$ over a single surface site using observations from the Spinning Enhanced Visible and Infrared Imager (SEVIRI) and Geostationary Earth Radiation Budget (GERB) instrument both flying on the Meteosat Second Generation series of satellites. In this paper the overall utility of the approach is investigated using a more comprehensive suite of observations, and the inherent uncertainties associated with the method are assessed. On the basis of these findings, the approach has been updated to account for the effects of varying dust layer altitude. Comparisons with colocated observations from the Aerosol Robotic Network (AERONET) and Multiangle Imaging Spectroradiometer (MISR) using the modified approach indicate that the visible optical thickness at $0.55 \mu \mathrm{m}, \tau_{055}$, can be obtained with an RMS uncertainty of $\sim 0.3$ over North Africa and Arabia during sunlit hours, while monthly maps of optical depth derived over this region through spring and summer of 2006 show similar variability to that identified in the long-term climatology provided by the Total Ozone Mapping Spectrometer (TOMS) Aerosol Index. The regional mean instantaneous cloud-free $\mathrm{LW}_{\mathrm{DRE}}$ and associated LW radiative efficiency estimated from GERB over the same period are relatively constant with season, ranging from 9 to $11 \mathrm{~W} \mathrm{~m}^{-2}$ and $16-20 \mathrm{~W} \mathrm{~m}^{-2} \tau_{055}^{-1}$, respectively.

Citation: Brindley, H. E., and J. E. Russell (2009), An assessment of Saharan dust loading and the corresponding cloud-free longwave direct radiative effect from geostationary satellite observations, J. Geophys. Res., 114, D23201, doi:10.1029/2008JD011635.

\section{Introduction}

[2] Over $50 \%$ of the global production of tropospheric aerosol particles consists of mineral aerosols originating from the deserts and their borders [Andreae et al., 1986]. These aerosols have many diverse effects on the Earth's climate system ranging from their impact on global biogeochemical cycles [e.g., Ridgwell, 2002; Jickells et al., 2005] to their proposed mitigating effect on extreme weather events [Dunion and Velden, 2004]. Key to their potential influence on future climate is their role in perturbing the Earth's top-of-atmosphere (TOA) radiation balance via their impact on both the reflected shortwave (SW) and the emitted longwave (LW) radiation [e.g., Hsu et al., 2000; Satheesh and Moorthy, 2005]. While the former might be expected to dominate over darker oceans, over bright desert surfaces the latter should become more critical, particularly during sunlit hours due to the thermal contrast between the temperature of the land surface and that of the dust layer. Work by Zhang and Christopher [2003], using colocated observations from instruments on the Terra satellite, taken

\footnotetext{
${ }^{1}$ Space and Atmospheric Physics Group, Blackett Laboratory, Imperial College London, London, UK.

Copyright 2009 by the American Geophysical Union. 0148-0227/09/2008JD011635\$09.00
}

daily at $\sim 1030 \mathrm{LT}$, indicates a regional mean instantaneous cloud-free direct LW effect of $\sim 7 \mathrm{~W} \mathrm{~m}^{-2}$ over the north African region. Perhaps more compellingly, Haywood et al. [2005] suggest that the summertime daytime TOA LW flux discrepancies of up to $50 \mathrm{~W} \mathrm{~m}^{-2}$ over western Africa seen between the UK Meteorological Office Numerical Weather Prediction model and Meteosat-7 could be explained by the absence of dust within the model.

[3] Recently, Brindley [2007, hereafter B07] used observations from the Spinning Enhanced Visible and InfraRed Imager (SEVIRI-1) [Schmetz et al., 2002] and Geostationary Earth Radiation Budget (GERB-2) [Harries et al., 2005] instruments flying on the Meteosat-8 satellite to estimate the dust loading and associated cloud-free TOA longwave direct radiative effect $\left(\mathrm{LW}_{\mathrm{DRE}}\right)$ over a single Sahelian surface site at local noon. The aim of this paper is to investigate whether the same simple technique can be applied more generally over the North African and Arabian continental regions located within the two instruments' field of view, encompassing a range of different local times. In section 2 we briefly introduce GERB and SEVIRI before summarizing the original methodology employed to detect dust and quantify the dust loading, with particular emphasis placed on the inherent assumptions that contribute to uncertainties in the final estimates of visible dust optical thicknesses. A relatively simple 
Table 1. Location and Temporal Coverage of AERONET Stations Used in This Study and Associated SEVIRI Viewing Zenith Angle $\theta_{\mathrm{v}}$

\begin{tabular}{lcccc}
\hline \multicolumn{1}{c}{ Station Name } & $\begin{array}{c}\text { Approximate } \\
\text { SEVIRI } \theta_{\mathrm{v}}\left({ }^{\circ}\right)\end{array}$ & $\begin{array}{c}\text { Latitude } \\
\left({ }^{\circ} \mathrm{N}\right)\end{array}$ & $\begin{array}{c}\text { Longitude } \\
\left({ }^{\circ} \mathrm{E}\right)\end{array}$ & $\begin{array}{c}\text { Months Used } \\
(2006)\end{array}$ \\
\hline Agoufou & 18.1 & 15.35 & -1.48 & Mar-Aug \\
Banizoumbou & 16.2 & 13.54 & 2.67 & $\begin{array}{c}\text { Mar-Aug } \\
\text { DMN Maine Soroa }\end{array}$ \\
& 20.9 & 13.22 & 12.02 & $\begin{array}{c}\text { Mar-May, } \\
\text { Jul-Aug }\end{array}$ \\
IER Cinzana & 17.1 & 13.28 & -5.93 & Mar-Aug \\
Saada & 37.9 & 31.63 & -8.16 & Mar-May \\
Sede Boker & 52.0 & 30.86 & 34.78 & Mar-Aug \\
Solar Village & 58.7 & 24.91 & 46.40 & Mar-Aug \\
\hline
\end{tabular}

modification to the approach is then introduced to address some of these issues. To give confidence in the general applicability of the modified approach, in section 3 the results from radiative transfer simulations are assessed in the context of colocated SEVIRI and ground-based Aerosol Observing Network (AERONET) [Holben et al., 1998] observations from sites located within the study region. To extend the analysis from point to larger spatial scales comparisons are also performed with matched retrievals from the Multiangle Imaging Spectroradiometer (MISR) instrument [Diner et al., 1998]. In section 4, a description of how this information can be used in conjunction with the GERB measurements to simultaneously diagnose the $\mathrm{LW}_{\text {DRE }}$ is provided, along with estimates of this quantity over the AERONET sites highlighted in section 3. Section 5 then presents a regional analysis of dust optical thickness and the associated longwave dust radiative efficiency, $\mathrm{LW}_{\mathrm{EFF}}$, for boreal spring and summer of 2006, and compares the findings with those of previous studies. Finally the conclusions which can be drawn from this work are presented in section 6 .

\section{Dust Detection and Quantification Methodology}

\subsection{Meteosat-8 Instrumentation}

[4] Meteosat-8, the first in the series of the Meteosat Second Generation satellites, was launched in August 2002, with a scientific payload consisting of the multichannel imager SEVIRI and the broadband radiometer GERB. The former consists of 11 narrowband spectral channels spanning the visible to midinfrared, with a spatial resolution of $3 \mathrm{~km}$ at nadir, and an additional high-resolution visible channel with enhanced spatial sampling of $1 \mathrm{~km}$ [Schmetz et al., 2002]. While SEVIRI can provide information pertaining to the atmospheric state at a $15 \mathrm{~min}$ temporal resolution, GERB is designed to simultaneously monitor variations in the Earth's top of atmosphere energy budget by inferring the broadband reflected shortwave and emitted longwave fluxes. Full details of the GERB instrument, including a description of the data processing chain and data archival arrangements are given by Harries et al. [2005]. GERB Averaged, Rectified and Geolocated (ARG) level 2 products were released for use by the scientific community on 11 May 2006 and can be accessed from the GERB Ground Segment Processing System (http://ggsps.rl.ac.uk).

[5] For the work presented in this paper we have used the GERB High-Resolution (HR) level 2 shortwave radiances and associated fluxes, contained within the GERB HR level 2 product. These GERB products utilize the SEVIRI observations to provide information on the scene variability within each GERB footprint and so interpolate the GERB observations of radiance from the GERB native resolution $(\sim 50 \times 50 \mathrm{~km}$ at nadir $)$ to a $3 \times 3$ SEVIRI pixel resolution $(\sim 10 \times 10 \mathrm{~km}$ at nadir) [Dewitte et al., 2007]. As part of the GERB processing, longwave fluxes are determined from the radiances by the application of an anisotropic factor, chosen according to the spectral behavior seen within the SEVIRI channels [Clerbaux et al., 2003]. The uncertainty introduced by this procedure is estimated to be no more than $2 \%$ of a given flux value for viewing zenith angles less than $60^{\circ}$.

\subsection{Separation of Cloudy/Clear Scenes}

[6] The method used to ascertain dust loading introduced by B07 is essentially an extension of the Infrared Difference Dust Index (IDDI) algorithm developed by Legrand and coworkers for use with Meteosat InfraRed (IR) channel radiances [Legrand et al., 2001]. It is designed to operate optimally over barren or sparsely vegetated regions and depends on first identifying cloud-free pixels over such areas. Cloudy points are identified by merging the results of the Nowcasting Satellite Application Facility (NWCSAF) cloud mask [Derrien and Le Gleau, 2005] with the GERB operational cloud flag [Ipé et al., 2004]. While both approaches employ SEVIRI observations they represent independent techniques, with the latter flag using visible SEVIRI channels only and the former incorporating both visible and infrared information. However, both masks tend to falsely flag thick dust outbreaks as cloud, so pixels identified as dusty using the NWCSAF dust detection algorithm [MétéoFrance, 2005] are reinstated with the cloud-free data. For this study the geographical and temporal coverage is restricted to land points between $20^{\circ} \mathrm{W}$ and $50^{\circ} \mathrm{E}$ and $0^{\circ}-40^{\circ} \mathrm{N}$ at an hourly resolution from 0800 to 1600 UTC through March-August 2006.

[7] To provide an indication of the ability of the cloud schemes to identify cloud-free pixels, level 1 and level 2 records from seven noncoastal AERONET stations located within the North African/Arabian region are used. The AERONET station location, SEVIRI viewing zenith angle, and the length of record considered is provided in Table 1. While level 1 records should contain all the measurements made at a given site, level 2 records represent the final cloud-screened and calibrated data [Smirnov et al., 2000]. Hence by comparing the two data sets one can obtain an indication of whether a particular location is subject to clear or cloudy conditions over a particular time period.

[8] Clearly, whenever a comparison is made between ground based point measurements and lower resolution top-of-atmosphere satellite observations, the disparity in scale would be expected to introduce differences in scene classification when the scene is heteorogeneous in space or time. We have attempted to minimize this effect by filtering both sets of observations: for AERONET over a half-hour sampling window centered on the SEVIRI acquisition time and for SEVIRI over an area of radius $20 \mathrm{~km}$ centered on the AERONET location. We then only retain measurements which show homogeneity for each record over the length/ 
Table 2. Truth Table Indicating the Numbers of Matched AERONET and SEVIRI Observations Identified as Cloudy and Clear by Their Respective Cloud-Screening Algorithms

\begin{tabular}{lcc}
\hline & \multicolumn{2}{c}{ AERONET } \\
\cline { 2 - 3 } SEVIRI & Cloud & Clear \\
\hline Cloud & 699 & 288 \\
Clear & 228 & 1524 \\
\hline
\end{tabular}

spatial scale considered. For AERONET this means that the scene is considered cloudy if a level 1 observation exists but no level 2 observations are present in the half-hour window and clear if the same number of level 1 and level 2 observations exist in this window. Similarly, for SEVIRI the scene is considered cloudy if all pixels within the $20 \mathrm{~km}$ radius are flagged as cloudy and clear if all pixels are unflagged. This approach makes the implicit assumption that homogeneity in space will translate to homogeneity in time and vice versa, but such strategies are commonly used in similar matching studies [e.g., Jiang et al., 2007]. We also note that in terms of their measurements of optical depth the AERONET stations chosen in this study are believed to be representative of scales of $>100 \mathrm{~km}$ (S. Kinne, personal communication, 2008).

[9] Table 2 provides an indication of the success of the SEVIRI masks in correctly identifying the scene type in terms of the number of true and false detections. Over the 6 month period analyzed $81 \%$ of the scene identifications match. Taking these results at face value and assuming that AERONET represents the "truth" and that the relative occurrence of clear and cloudy cases is representative of the study region as a whole, this would imply that our retrievals will have a $16 \%$ chance of missing clear events and a $13 \%$ chance of including cloud contaminated cases. The relatively even split between false cloud and false clear detections indicates that SEVIRI and AERONET detect approximately the same overall level of cloud. This is consistent with the difference in spatial scale being the cause of scene type discrepancies, despite our efforts to ensure homogeneity.

[10] Decomposing the results according to AERONET site (not shown), it is noticeable that the detection scheme appears to consistently underestimate cloud at DMN Maine Soroa. While it is difficult to ascertain exactly why this is the case it should be noted that no level 2 observations are available at this site from mid-May to late July 2006 despite the presence of level 1 data. In generating the AERONET scene identification we are implicitly assuming that level 2 AERONET observations are only removed if cloud is present and not for any other reason (for example, poor data quality). This could lead to our number of cloud identifications based on AERONET being biased high and inflate the apparent number of false clear detections from SEVIRI. Removing DMN Maine Soroa from the analysis would reduce the number of false clear detections by $\sim 40 \%$. Conversely, at Solar Village too much cloud is detected, particularly later in the day as the terminator approaches. The tendency to overestimate cloud amount toward dusk is a known problem in the GERB cloud detection and an improved scheme is currently under development (A. Ipé, personal communication, 2008).
Over the remaining five sites the percentage of correct matches exceeds $85 \%$.

\subsection{Quantification of Dust Loading}

[11] The next step requires the identification of at least one dust-free observation for each individual time slot and pixel within a set running window of 28 days. The period is chosen to maximize the chance of observing dust-free conditions at all pixels, while also being short enough to reduce the impact of seasonal changes in surface emissivity; however, in reality, some level of background dust loading is generally always present. The selection is achieved by estimating the pristine sky brightness temperature at $10.8 \mu \mathrm{m}\left(\mathrm{T}_{\mathrm{B} 108}\right)$ using colocated values of surface temperature, $\mathrm{T}_{\mathrm{sfc}}$, and column water vapor, $\mathrm{w}$, from European Centre for Medium Range Weather Forecasting (ECMWF) analyses. At $1200 \mathrm{UTC}, \mathrm{T}_{\mathrm{sfc}}$ and $\mathrm{w}$ can be extracted directly from the analysis fields; at other times they are obtained via linear interpolation using the analysis fields at 0600 UTC or 1800 UTC as appropriate. The estimates of pristine sky $T_{B 108}$ are then compared to the observed cloud-free $T_{B 108}$. For each time slot and pixel, the day showing the minimum difference between the estimated pristine $T_{\mathrm{B} 108}$ and the observed value is considered dust-free and denoted $T_{B 108 d f}$. An estimate of the dust-free $10.8 \mu \mathrm{m}$ brightness temperature, $\mathrm{T}_{\mathrm{B} 108 \mathrm{dfe}}$, for all other cloud-free days within the running window is obtained by adjusting the $T_{B 108 d f}$ value using:

$$
\mathrm{T}_{\mathrm{B} 108 \mathrm{dfe}}=\mathrm{T}_{\mathrm{B} 108 \mathrm{df}}+\Delta \mathrm{T}_{\mathrm{B} 108 \mathrm{df}}
$$

where

$$
\Delta \mathrm{T}_{\mathrm{B} 108 \mathrm{df}}=\mathrm{c}_{1} \times \Delta \mathrm{T}_{\mathrm{sfc}}+\mathrm{c}_{2} \times \Delta \mathrm{w}
$$

in order to account for the changes in surface temperature and column water vapor that have occurred between each of these days and the dust-free day $\left(\Delta \mathrm{T}_{\mathrm{sfc}}\right.$ and $\Delta \mathrm{w}$, respectively). Values of $c_{1}$ and $c_{2}$ are derived from a suite of radiative transfer simulations and depend on the viewing zenith angle (see B07 for full details). The dustonly impact on $\mathrm{T}_{\mathrm{B} 108}$ can then be obtained by taking the difference:

$$
\Delta \mathrm{T}_{\mathrm{B} 108}=\mathrm{T}_{\mathrm{B} 108 \mathrm{dfe}}-\mathrm{T}_{\mathrm{B} 108}
$$

Essentially, if the changes in atmospheric conditions have been correctly accounted for in the derivation of $\mathrm{T}_{\mathrm{B} 108 \mathrm{df} \text {, }}$, then $\Delta \mathrm{T}_{\mathrm{B} 108}$ should only contain a dust signal. However, this dust signal will incorporate not only the effect of the dust concentration (or optical thickness) but also the altitude (or temperature) of the dust layer. To provide an indication of the sensitivity of the signal to both quantities, Figure 1a shows simulations of $\Delta \mathrm{T}_{\mathrm{B} 108}$ as a function of optical thickness at 0.55 microns $\left(\tau_{055}\right)$ calculated for a dust layer situated at a variety of heights in the same atmospheric profile (shown in Figure 1b). At a given $\tau_{055}$, as the dust layer altitude increases, $\Delta \mathrm{T}_{\mathrm{B} 108}$ also increases due to the reduction in atmospheric temperature; this increase with altitude is more marked at higher optical thicknesses because $T_{\mathrm{B} 108}$ is dominated by emission from 

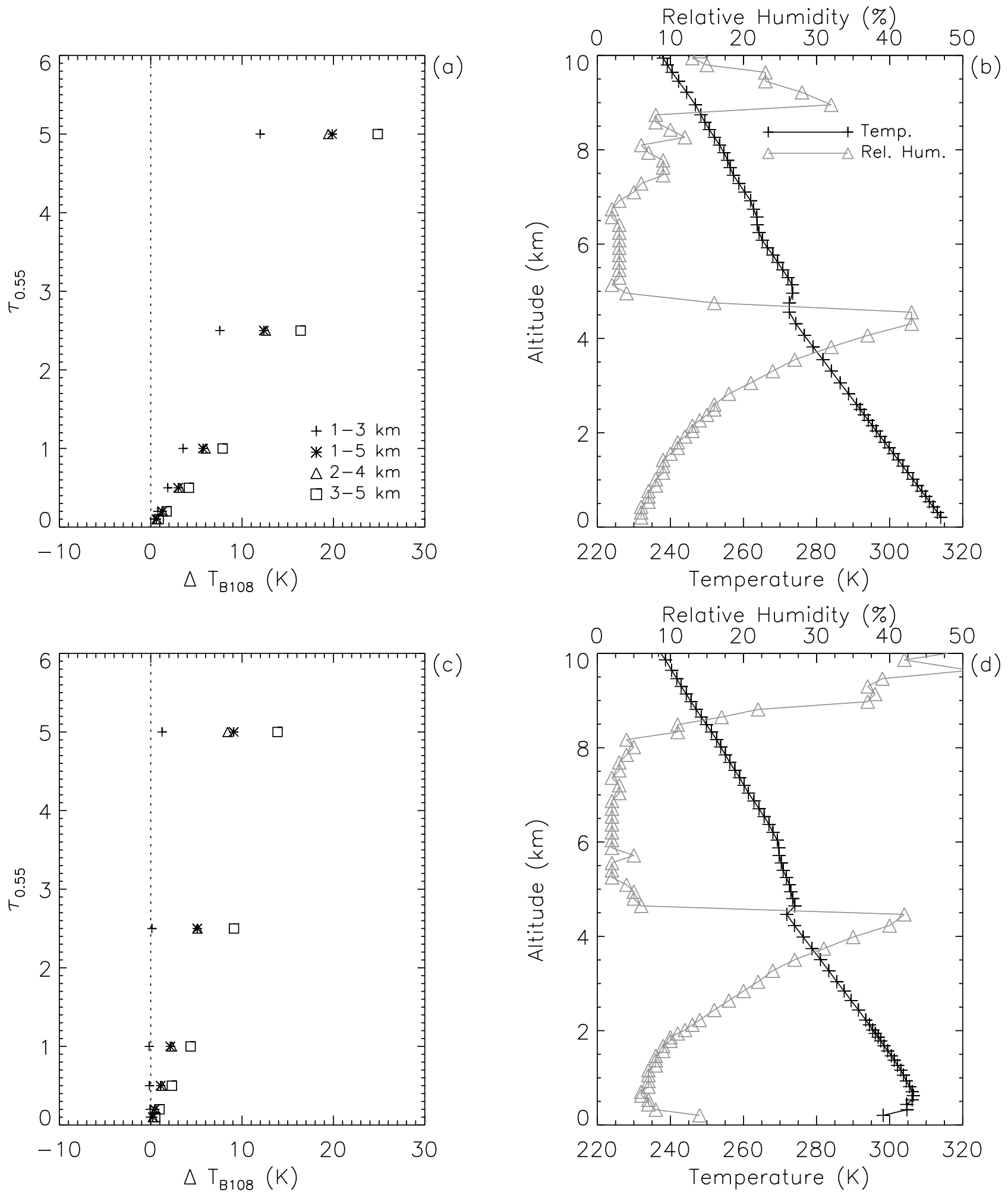

Figure 1. (a) Simulated variation of $\Delta \mathrm{T}_{\mathrm{B} 108}$ as a function of dust optical thickness at $0.55 \mu \mathrm{m}, \tau_{055}$, for a variety of dust layer heights and layer thicknesses using (b) the atmospheric temperature and humidity profiles measured at Niamey, Niger at 1730 UTC on 6 March 2006. (c) As in Figure 1a but for 05:30 UTC on the same day. (d) Relevant atmospheric profiles of temperature and humidity.

the dust layer itself. For the same reason, for a given dust layer height, the sensitivity of the dust signal tends to asymptote at higher optical thicknesses: adding extra dust makes no difference to the signal because all of the emission is already coming from the top of the dust layer. Figures 1c-1d show analogous information for an alternative profile measured at the same location and on the same day but at an earlier local time. In this case there 


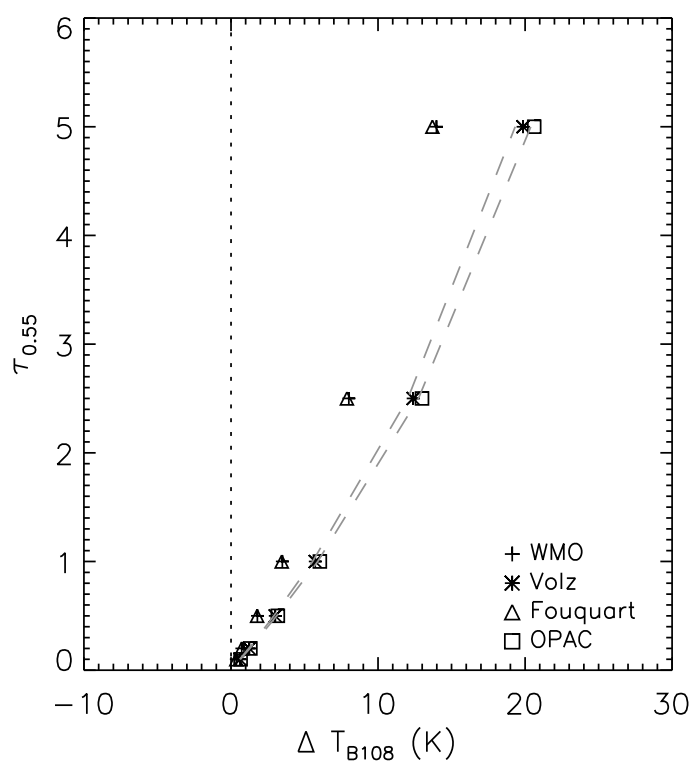

Figure 2. Simulated sensitivity of $\Delta \mathrm{T}_{\mathrm{B} 108}$ to changes in $\tau_{055}$ for four different dust models. The dust layer is constrained to be between 1 and $5 \mathrm{~km}$, a surface emissivity of 0.95 is assumed, and the profile shown in Figure $1 \mathrm{~b}$ is used. Dashed lines show the effect of a variation in surface emissivity of between 0.93 and 0.97 on values of $\Delta T_{\mathrm{B} 108}$ obtained using the Volz dust model.

is a relatively strong surface temperature inversion such that inserting a dust layer in the lowest portion of the atmosphere results in a negative $\Delta \mathrm{T}_{\mathrm{B} 108}$ signal.

[12] The strength of the $\Delta T_{B 108}$ signal will also be dependent on the dust mineralogy (or complex refractive index) and the size distribution. Highwood et al. [2003] suggest that in the infrared uncertainties in the former quantity dominate over those in the latter. Accordingly, Figure 2 again indicates $\Delta \mathrm{T}_{\mathrm{B} 108}$ as a function of $\tau_{055}$, but in this case the dust is situated within a fixed layer and instead the optical properties are varied. The dust models considered are those described by Brindley and Russell [2006], with refractive indices due to the World Meteorological Organisation [World Climate Program, 1986], Fouquart et al. [1987], Volz [1973], and Hess et al. [1998]. The properties obtained for the first three of these models are obtained using the same observationally based size distribution (J. Haywood, personal communication, 2004), while those for the last model are taken directly from the Optical Properties of Clouds and Aerosol (OPAC) dust representation. Interestingly, the dependence of $\Delta \mathrm{T}_{\mathrm{B} 108}$ on $\tau_{055}$ appears to be similar for the WMO and Fouquart models and for the OPAC and Volz models but shows a markedly different gradient between these two pairs, with the latter two representations showing a greater increase in $\Delta \mathrm{T}_{\mathrm{B} 108}$ for a given increase in $\tau_{055}$ up to the point where the $\Delta \mathrm{T}_{\mathrm{B} 108}$ signal saturates. The dashed lines on Figure 2 indicate the effect of varying the $10.8 \mu \mathrm{m}$ surface emissivity, $\varepsilon_{\mathrm{s} 108}$, from 0.93 to 0.97 on the values of $\Delta \mathrm{T}_{\mathrm{B} 108}$ derived for the Volz dust model. Clearly, over the values considered here, representative of the range of $\varepsilon_{\mathrm{s} 108}$ derived over the Sahara [Trigo et al., 2008], $\Delta \mathrm{T}_{\mathrm{B} 108}$ shows little change; a similar lack of sensitivity is seen for the other three dust models.

\section{Dust Quantification Validation \\ 3.1. Simulated Relationship}

[13] Given the sensitivity analyses highlighted in section 2, an unambiguous attempt to directly relate $\Delta \mathrm{T}_{\mathrm{B} 108}$ to $\tau_{055}$ without accounting for dust layer height or type would appear to be somewhat ambitious. Nevertheless, the previous work by B07 suggests that at least for one site and at one local time the signal is highly correlated $(\mathrm{R}=0.88)$ to visible optical thickness. A similar degree of correlation between observations from a number of Sahelian AERONET sites and colocated 1200 UTC dust infrared brightness temperature signals derived from Meteosat is also seen by Verge-Depre et al. [2006]. In this section we assess whether this level of correlation holds over a wider range of sites and times.

[14] With this in mind, Figure 3a shows $\tau_{055}$ against $\Delta \mathrm{T}_{\mathrm{B} 108}$ simulated using ECMWF analyses as input to the Moderate Resolution Radiative Transfer Code (MODTRAN) version 4 [Anderson et al., 2000] for a viewing zenith angle, $\theta_{\mathrm{v}}$, of $20^{\circ}$. Atmospheric profiles of temperature and water vapor were taken from 10 locations across the $20^{\circ} \mathrm{N}$ latitude band, spanning $10^{\circ} \mathrm{W}$ to $35^{\circ} \mathrm{E}$, at $1200 \mathrm{UTC}$ for March and June 2006. Spectral pristine sky radiances at the TOA were output by MODTRAN in $10^{\circ}$ increments of view angle from nadir to $70^{\circ}$ before being convolved with the Meteosat- 8 midinfrared SEVIRI channel spectral response functions. The simulations were then repeated but with a dust layer of variable physical and optical thickness inserted into the profile. To cover the range of dust altitudes inferred from space-borne LIDAR observations over northern Africa [Liu et al., 2008], the lower boundary of the layer could vary between 1 and $2.5 \mathrm{~km}$ while the upper boundary could vary between 2 and $7 \mathrm{~km}$. Similarly, the optical thickness of the resulting layer was allowed to vary randomly, but the overall distribution used was constrained to have a mean $\tau_{055}$ value of 1.0 and a standard deviation of 1.0. In practice, all values of $\tau_{055}$ lie between 0 and 5. Given the sensitivities seen in the previous section, the dust properties used were either due to Fouquart or Volz.

[15] As seen in Figure 2, for a given value of $\tau_{055}$ the Volz representation tends to give a larger $\Delta \mathrm{T}_{\mathrm{B} 108}$ response relative to Fouquart: this difference in sensitivity is consistent with that shown by Haywood et al. [2005] when considering the effect of increasing dust optical thickness on broadband TOA LW fluxes. The level of sensitivity shown by the Volz simulations would appear more consistent with the fit derived from the observational data used in B07, shown by the dashed black line in Figure 3a. However, it is apparent that the variation in height of the dust layer, and hence in the contrast between the effective dust emitting temperature and the surface introduces a large scatter into the $\Delta \mathrm{T}_{\mathrm{B} 108}$ versus $\tau_{055}$ relationship. This effect is illustrated in Figure 3b, which stratifies the Volz simulations shown in Figure 3a according to the contrast between the mean temperature of the dust layer and the surface. Once such stratification is performed the relationship between $\tau_{055}$ and $\Delta \mathrm{T}_{\mathrm{B} 108}$ in each temperature band 


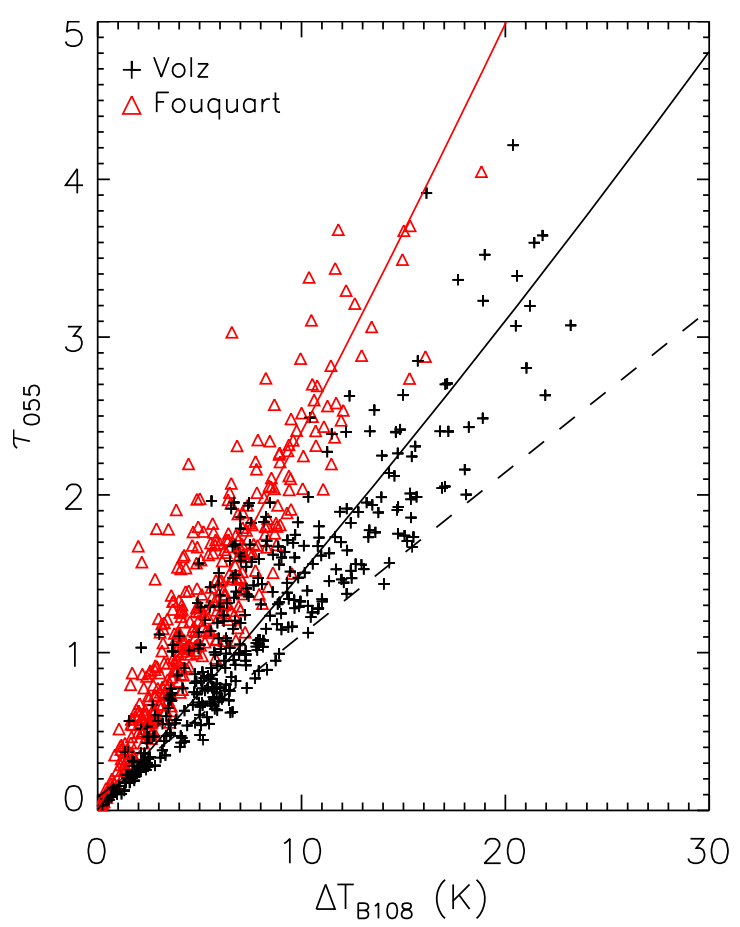

(a)

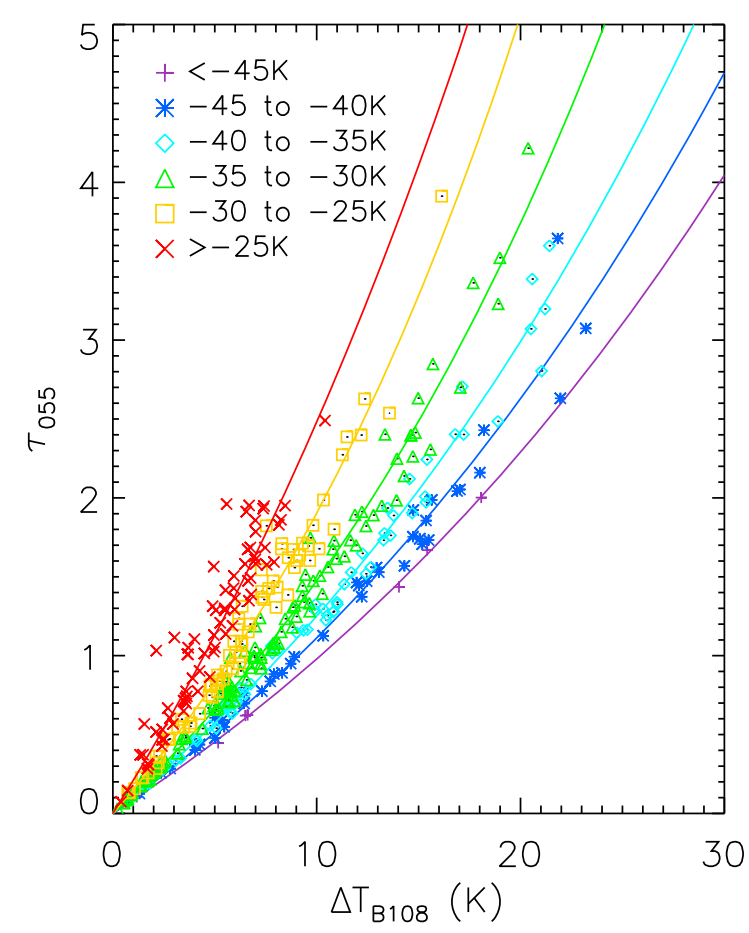

(b)

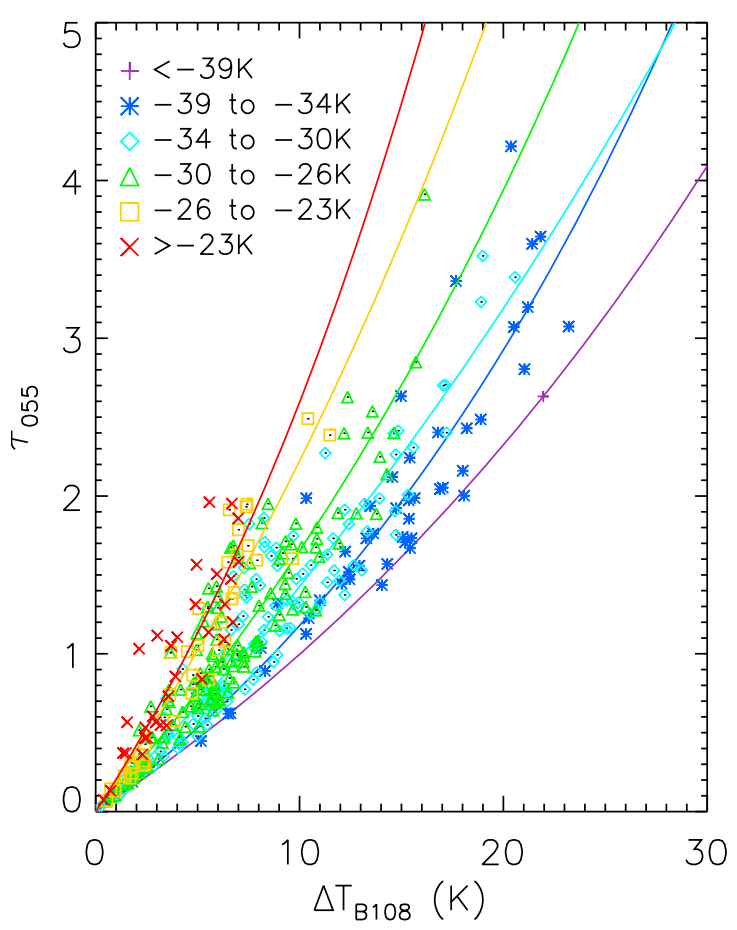

(c)

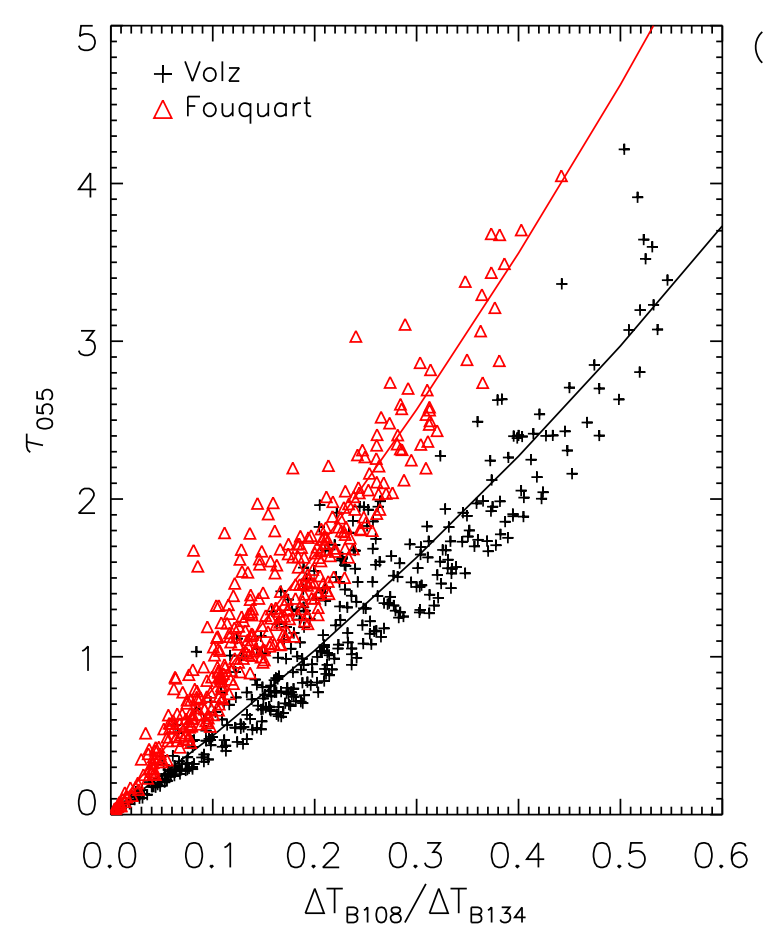

Figure 3. (a) Simulated values of $\Delta \mathrm{T}_{\mathrm{B} 108}$ as a function of $\tau_{055}$ for the Volz and Fouquart dust models at viewing zenith angles of $20^{\circ}$ for the range of ECMWF analysis fields and dust layer heights described in the text. (b) Volz simulations stratified according to mean dust layer temperature minus skin temperature: the temperature difference range encompassed by each color is indicated in the legend. (c) As in Figure 3a but simulations stratified according to $\Delta \mathrm{T}_{\mathrm{B} 134}$ : again, the range of values encompassed by each color for this viewing zenith angle is shown in the legend. (d) Volz and Fouquart $\Delta T_{B 108} / \Delta T_{B 134}$ as a function of $\tau_{055}$. 
Table 3. Root-Mean-Square (rms) Error and Bias in the Fitted Values of $\tau_{055}$ for the Various Cases Considered in This Study as a Function of Viewing Zenith Angle $\theta_{\mathrm{v}}{ }^{\mathrm{a}}$

\begin{tabular}{|c|c|c|c|c|c|c|c|c|}
\hline \multirow[b]{2}{*}{$\underline{\theta_{\mathrm{v}}(\mathrm{deg})}$} & \multicolumn{2}{|c|}{ Volz $\Delta \mathrm{T}_{\mathrm{B} 108}$} & \multicolumn{2}{|c|}{ Volz $\Delta \mathrm{T}_{\mathrm{B} 108} / \Delta \mathrm{T}_{\mathrm{B} 134}$} & \multicolumn{2}{|c|}{ Fouquart $\Delta \mathrm{T}_{\mathrm{B} 108}$} & \multicolumn{2}{|c|}{ Fouquart $\Delta \mathrm{T}_{\mathrm{B} 108} / \Delta \mathrm{T}_{\mathrm{B} 134}$} \\
\hline & $\mathrm{rms}$ & Bias & $\mathrm{rms}$ & Bias & $\mathrm{rms}$ & Bias & $\mathrm{rms}$ & Bias \\
\hline 0 & 0.313 & -0.03 & 0.236 & -0.03 & 0.313 & -0.09 & 0.240 & -0.03 \\
\hline 10 & 0.314 & -0.03 & 0.236 & -0.03 & 0.307 & -0.05 & 0.240 & -0.03 \\
\hline 20 & 0.316 & -0.03 & 0.238 & 0.00 & 0.308 & -0.05 & 0.241 & -0.03 \\
\hline 30 & 0.323 & -0.04 & 0.244 & -0.03 & 0.314 & -0.08 & 0.243 & -0.03 \\
\hline 40 & 0.328 & -0.03 & 0.252 & -0.02 & 0.316 & -0.08 & 0.247 & -0.03 \\
\hline 50 & 0.337 & -0.02 & 0.268 & 0.00 & 0.319 & -0.07 & 0.255 & -0.02 \\
\hline 60 & 0.362 & -0.02 & 0.298 & 0.00 & 0.330 & -0.04 & 0.272 & -0.01 \\
\hline 70 & 0.419 & -0.02 & 0.367 & 0.00 & 0.361 & -0.03 & 0.317 & 0.00 \\
\hline
\end{tabular}

${ }^{\mathrm{a}}$ The simulations encompass a total column water vapor range of $2-33 \mathrm{~mm}$ and a surface skin temperature range of $300-335 \mathrm{~K}$.

tends to follow a reasonably well defined exponential curve of the form:

$$
\tau_{055}=a_{1}\left(\theta_{v}\right) \times a_{2}\left(\theta_{v}\right)^{\Delta \mathrm{T}_{\mathrm{B} 108}}-a_{3}\left(\theta_{v}\right)
$$

where the coefficients $\mathrm{a}_{1}, \mathrm{a}_{2}$, and $\mathrm{a}_{3}$ are solely a function of viewing zenith angle, $\theta_{\mathrm{v}}$.

[16] Hence to improve the general applicability of the B07 approach, a proxy measure of the surface/dust layer temperature contrast is required. In principle this could be achieved through the use of colocated space-borne LIDAR observations (e.g., CALIPSO) [Winker et al., 2007] in combination with either temperature soundings or operational analyses. However, the former observations would only be available over a given location at most twice per day and so this approach would remove the principal advantage of the excellent temporal sampling offered by SEVIRI. In addition, the approach suggested here also allows retrievals to be made throughout sunlit hours over the entire North African and Arabian region rather than over the rather narrow swath widths available from LIDAR. Instead, in Figure $3 \mathrm{c}$ an attempt is made to stratify the Volz simulations using $\Delta \mathrm{T}_{\mathrm{B} 134}$, where

$$
\Delta \mathrm{T}_{\mathrm{B} 134}=\mathrm{T}_{\mathrm{B} 108 \mathrm{dfe}}-\mathrm{T}_{\mathrm{B} 134}
$$

Here $\mathrm{T}_{\mathrm{B} 134}$ is the brightness temperature measured by the $13.4 \mu \mathrm{m}$ SEVIRI channel. The idea here is that this channel is less sensitive to the presence of dust directly but sounds a region which would be expected to contain the dust layer. Hence the difference in (5) should be directly related to the lapse rate of the atmospheric profile. Figure $3 \mathrm{c}$ illustrates that the approach has skill in discriminating between different temperature bands, while Figure $3 \mathrm{~d}$ shows how this information can be decomposed into one overall relationship by plotting $\tau_{055}$ against the ratio $\Delta \mathrm{T}_{\mathrm{B} 108} /$ $\Delta \mathrm{T}_{\mathrm{B} 134}$. The amount of scatter is significantly reduced relative to that seen in Figure 3a.

[17] Table 3 indicates the improvement that is obtained when fitting $\tau_{055}$ as a function of $\Delta \mathrm{T}_{\mathrm{B} 108} / \Delta \mathrm{T}_{\mathrm{B} 134}$ rather than $\Delta \mathrm{T}_{\mathrm{B} 108}$ alone. Here, for each dust representation, half of the simulations have been used to fit equations of the form given in (4) both as it stands and with $\Delta \mathrm{T}_{\mathrm{B} 108}$ replaced by $\Delta \mathrm{T}_{\mathrm{B} 108} / \Delta \mathrm{T}_{\mathrm{B} 134}$. The remaining half of the simulations are used as a test set to generate the associated root-meansquare (rms) error and bias that would be present in the values of $\tau_{055}$ that are obtained from these fits compared to the true values. These values are provided for each case in
Table 3. Note that in terms of both the RMS and bias the quality of fit obtained using the test set simulations is always within 0.03 of that seen from the simulations on which the fit was made. In effect, assuming that the simulations encompass a realistic combination of atmospheric conditions and dust loadings and that one individual dust model is sufficient to represent all dust types, these errors represent the highest possible accuracy that could be expected using the approach described here to derive $\tau_{055}$. In practice, a number of uncertainties in the technique would be expected to reduce the accuracy of the final optical thickness estimates. The largest uncertainty concerns the estimate of pristine sky brightness temperature, $\mathrm{T}_{\mathrm{B} 108 \mathrm{dfe}}$. B07 suggests that typical uncertainties in the $T_{\text {sfc }}$ and $\mathrm{W}$ records would result in a random uncertainty in $\Delta \mathrm{T}_{\mathrm{B} 108}$ (and $\Delta \mathrm{T}_{\mathrm{B} 134}$ ) which has a standard deviation of the order $\pm 1 \mathrm{~K}$. Incorporating this uncertainty in the distribution of simulated $\Delta T_{B}$ values would increase the RMS error in the fitted values over the entire $\tau_{055}$ distribution by approximately 0.1 .

\subsection{Observed Results}

\subsubsection{Comparison With AERONET Measurements}

[18] The question arises as to whether these theoretical relationships are actually seen in the observational data record. To assess this, aerosol optical thickness records from the AERONET sites identified in section 2.1 are employed in conjunction with colocated SEVIRI 10.8 and $13.4 \mu \mathrm{m}$ brightness temperature observations. For consistency with the simulations, AERONET optical thicknesses at $0.675 \mu \mathrm{m}$ are converted to equivalent values at $0.55 \mu \mathrm{m}$ using the inferred Angström coefficient over the 0.44 to $0.87 \mu \mathrm{m}$ range. Employing the same homogeneity criteria described in section 2.2, for a given AERONET site, the mean of all optical thickness values within \pm 15 min of a given SEVIRI observation time are matched with the mean SEVIRI $\Delta \mathrm{T}_{\mathrm{B} 108}$ and $\Delta \mathrm{T}_{\mathrm{B} 134}$ values calculated from cloudfree observations within a $20 \mathrm{~km}$ radius of the site. To filter for dust, an additional requirement that AERONET retrievals show an Ångström coefficient of less than 1 is also applied. This test removes $\sim 5 \%$ of the total number of matched points.

[19] Figure 4a shows the matched AERONET optical thicknesses against SEVIRI $\mathrm{T}_{\mathrm{B} 108}$ signals at 1200 UTC over the period March-August 2006 for the seven sites highlighted here. In Figure $4 \mathrm{a}$, no attempt has been made to correct for changes in surface temperature and humidity that may have occurred between the day identified as pristine 

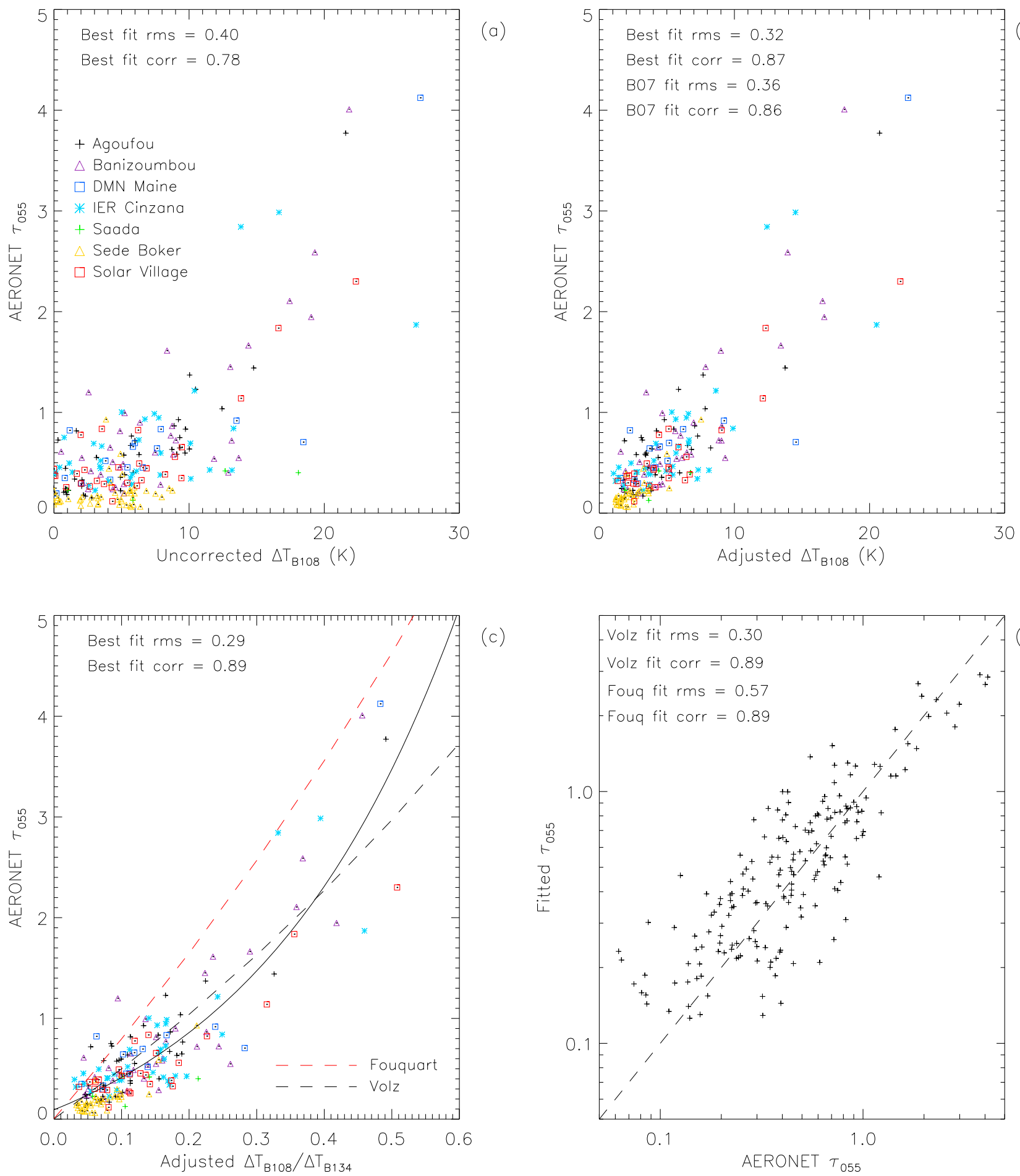

(c)

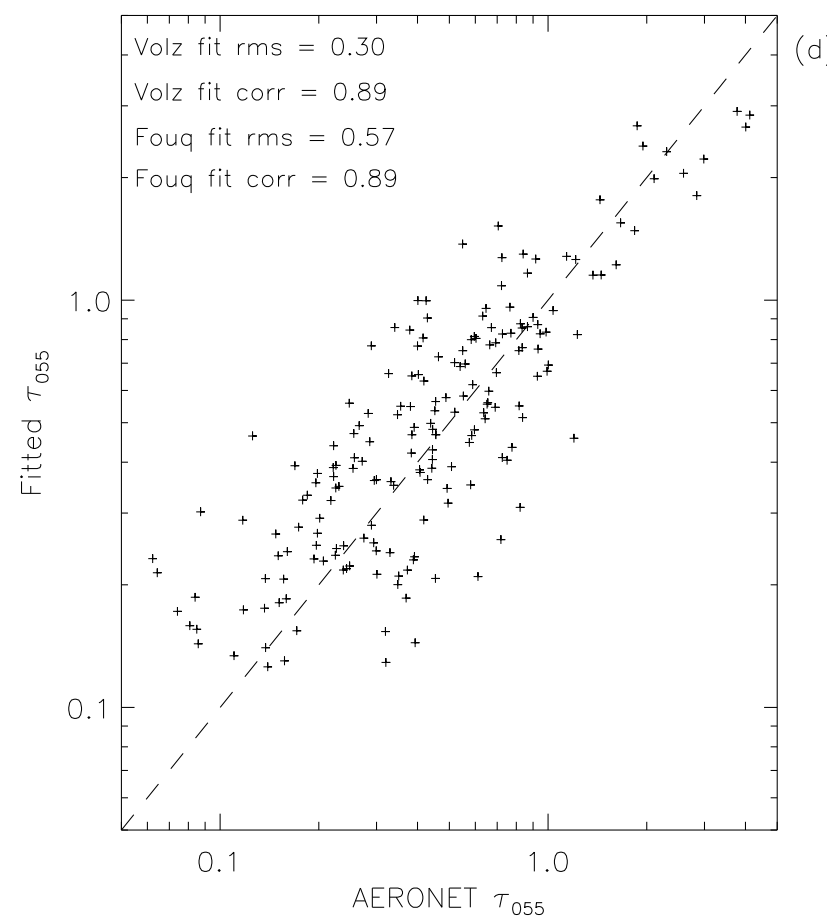

Figure 4. The $\tau_{055}$ derived from AERONET observations versus colocated (a) uncorrected $\Delta \mathrm{T}_{\mathrm{B} 108}$, (b) corrected $\Delta \mathrm{T}_{\mathrm{B} 108}$, and (c) corrected $\Delta \mathrm{T}_{\mathrm{B} 108} / \Delta \mathrm{T}_{\mathrm{B} 134}$ over the sites indicated at $1200 \mathrm{UTC}$. The solid line in Figure $4 \mathrm{c}$ shows the best fit assuming a relationship of the form given in equation (4). The dashed lines show the equivalent relationships derived from the Fouquart and Volz simulations performed in section 3.1 for a viewing zenith of $20^{\circ}$. (d) Observed AERONET versus fitted $\tau_{055}$ using theoretical Volz fits.

and on subsequent dusty days within the record. In essence this is equivalent to the original IDDI approach [Legrand et al., 2001]. For comparison, Figure $4 \mathrm{~b}$ shows the relationship between $\tau_{055}$ and the corrected $\Delta \mathrm{T}_{\mathrm{B} 108}$ derived from equation (3). Fitted $\tau_{055}$ values assuming a relationship of the form given in equation (4) were obtained. While the RMS difference between these fitted values and the observed $\tau_{055}$ is 0.40 in Figure $4 \mathrm{a}$, in Figure $4 \mathrm{~b}$ this is reduced to 0.32 , showing that, similar to the results from B07, the additional correction reduces the scatter in the relationship. 
For completeness, using the linear fit derived in B07 results in an RMS difference of 0.36 . Figure $4 \mathrm{c}$ shows $\tau_{055}$ as a function of $\Delta \mathrm{T}_{\mathrm{B} 108} / \Delta \mathrm{T}_{\mathrm{B} 134}$. As expected from the simulations in the previous section, the scatter in the relationship is reduced further with a best fit RMS of 0.29 and an enhanced correlation. Examples of the Volz and Fouquart fits at a viewing angle of $20^{\circ}$ are also shown for comparison. While these both tend to show flatter behavior than the best fit curve, the Volz fit appears to more closely mimic the observed relationship. This visual impression is confirmed by the RMS values and biases seen between the fitted and observed $\tau_{055}$ values using the two sets of fit coefficients. Volz RMS and bias values are 0.30 and -0.02 , respectively, while the equivalent Fouquart values are 0.57 and -0.41 . Figure 4d illustrates the Volz fitted values versus the observed $\tau_{055}$ from AERONET on a log-log scale. The degree of agreement obtained is close to that predicted from the simulations given the likely uncertainties in the ECMWF analysis fields (section 3.1).

[20] Although these results for 1200 UTC suggest that the adjusted method can be successfully applied over a number of different locations, its general applicability at different times of day would still seem an open question. However, given the longitudes of the sites analyzed, the range of local times spanned in the comparison encompasses $\sim 1130$ to 1500 LT. The sites at the extremes of this range (Saada and Solar Village) do not appear to show markedly different behavior than that seen at the remainder of the locations. Again, this suggests that over this time period systematic differences in atmospheric structure are not manifested in the observations. Given that the method depends on an adequate correction to account for the effects of surface temperature and humidity on the $\mathrm{T}_{\mathrm{B} 108}$ signal, a potentially more important question concerns the impact of using interpolated ECMWF fields to perform the correction away from the 0600,1200 , and 1800 UTC reporting times available here. To assess this, Figure 5 shows uncorrected $\Delta \mathrm{T}_{\mathrm{B} 108}$ (analogous to Figure $4 \mathrm{a}$ ), corrected $\Delta \mathrm{T}_{\mathrm{B} 108}$ (analogous to Figure $4 \mathrm{~b}$ ), and $\Delta \mathrm{T}_{\mathrm{B} 108} / \Delta \mathrm{T}_{\mathrm{B} 134}$ (analogous to Figure $4 \mathrm{c}$ ) signals as a function of $\tau_{055}$ over the AERONET sites every $2 \mathrm{~h}$ from 0800 to 1600 UTC (excluding 1200 UTC). For each time the best fit to the data assuming a relationship of the form given in equation (4) was calculated. The linear correlation coefficient between the $\tau_{055}$ values obtained using this fit and those from AERONET is shown in Figures $5 \mathrm{a}-5 \mathrm{c}$ along with the RMS difference. Finally, for each time, scatterplots of $\tau_{055}$ derived using the Volz fits on $\Delta \mathrm{T}_{\mathrm{B} 108} / \Delta \mathrm{T}_{\mathrm{B} 134}$ against AERONET $\tau_{055}$ are also provided with the associated RMS difference and linear correlation coefficient.

[21] Looking first at the uncorrected $\Delta \mathrm{T}_{\mathrm{B} 108}$ versus $\tau_{055}$ figures, the level of correlation peaks between 1000 and 1400 UTC (Figures 5e and 5i) before markedly decreasing at the earlier and later times. Although a similar pattern is seen in the corrected $\Delta \mathrm{T}_{\mathrm{B} 108}$ observations it is substantially flattened, and for each time slot the overall correlation is improved. A further flattening and improvement in correlation is seen when $\tau_{055}$ is plotted as a function of $\Delta T_{B 108} /$ $\Delta \mathrm{T}_{\mathrm{B} 134}$, with a concomitant reduction in RMS differences between the predicted and observed $\tau_{055}$ values. Using the appropriate Volz fits to obtain $\tau_{055}$ from $\Delta \mathrm{T}_{\mathrm{B} 108} / \Delta \mathrm{T}_{\mathrm{B} 134}$ results in a level of agreement with AERONET that is close to that seen in the equivalent best fit case for all times considered. It is interesting to note that the most marked improvement in performance occurs at times which are relatively far from the 6 hourly ECMWF analysis times available to this study. This would suggest that the interpolation of the 6 hourly ECMWF fields to intermediate times is not compromising the retrieval approach.

[22] For completeness site specific results are provided in Figure 6. In Figure 6, time series of "daily mean" $\tau_{055}, \tau_{\mathrm{d}}$, derived from AERONET and from the appropriate Volz fit applied to $\Delta \mathrm{T}_{\mathrm{B} 108}$ are shown along with the correlation, RMS difference and mean bias between the two daily mean records. Daily means are calculated if both records show three or more matched $\tau_{055}$ values between 0800 and 1600 UTC on a given day. This requirement resulted in the retention of very few days over the Saada site such that the results for this location are not shown. The vertical lines indicate the standard deviation in the values over the day. As might be expected from the previous results, in general the level of agreement is good. The fitted values do tend to exhibit noisier behavior than their AERONET counterparts, both from day to day, and, unsurprisingly given the slight variation in the level of correlation seen at different UTC times, also through the course of a single day. While enhanced values of $\tau_{\mathrm{d}}$ and associated standard deviation derived from SEVIRI may be a signal of residual cloud contamination, sporadic periods of very heavy dust loading in the AERONET record tend to be underestimated by the Volz fits (for example in early March over Banizoumbou (Figure 6b) and IER Cinzana (Figure 6d)). The degree of agreement between the two time series at each site does not show any obvious temporal dependence, and there are no clear patterns of behavior as a function of viewing zenith. Resolving the data into matched hourly time series does not materially change the level of agreement seen between the AERONET and SEVIRI based records with the additional scatter reducing the correlations by at most 0.1 and typically less than 0.05. Similarly, RMS differences are altered by less than 0.02 .

\subsubsection{Comparison With Satellite-Based Retrievals}

[23] Although AERONET sites provide an invaluable set of ground truth measurements against which satellite retrievals can be validated, the limited number of stations, particularly in the heart of the Sahara desert makes it difficult to assess whether the level of agreement seen in section 3.2.1 is consistently achieved over the whole of the study region. To address this, in this section the SEVIRIbased optical thicknesses are compared to retrievals made using observations from MISR, flying on board the Terra satellite. Comparisons with AERONET measurements over four desert sites suggest an uncertainty of $\sim 0.08$ in the 17.6 $\mathrm{km}$ resolution MISR products such as those employed here [Martonchik et al., 2004]. Although the MISR retrievals also suffer from the same lack of validating observations in the same regions, given the different techniques and spectral ranges used to infer the aerosol loading, a consistent match between the SEVIRI and MISR values across the study region would give confidence that the method outlined here is capturing the spatial behavior of the true aerosol field.

[24] Figures 7 and 8 show density plots of $\tau_{055}$ derived from $\Delta \mathrm{T}_{\mathrm{B} 108}$ using the Volz fits against colocated MISR retrievals. The colocation procedure involves binning both 

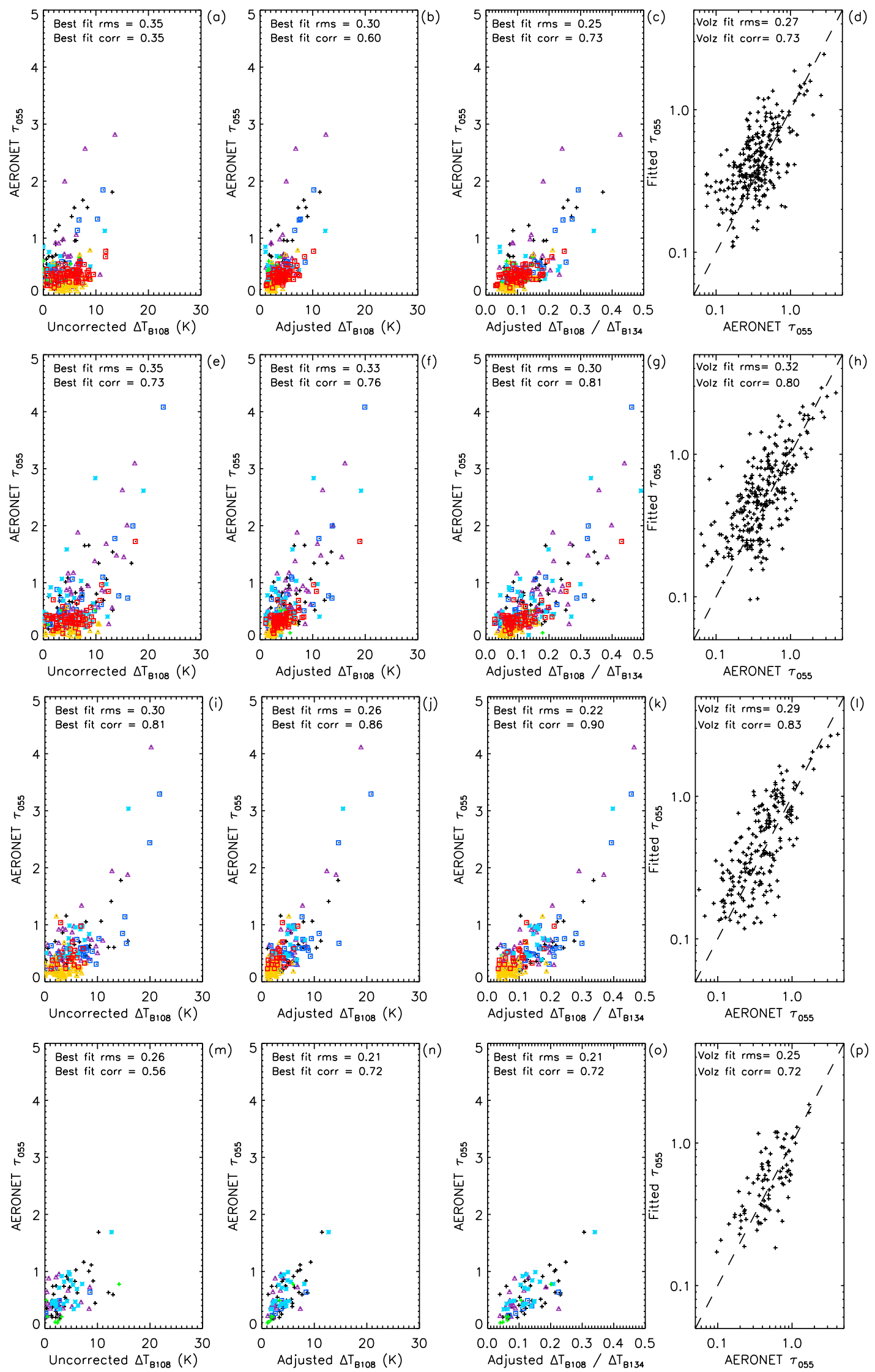

Figure 5. (a)-(d) As in Figures 4a-4d for 0800 UTC; (e)-(h) As in Figures 4a-4d for 1000 UTC; (i)-(l) As in Figures 4a-4d for 1400 UTC; (m)-(p) As in Figures 4a-4d for 1600 UTC. Color coding and symbols are as defined in Figure 4. 

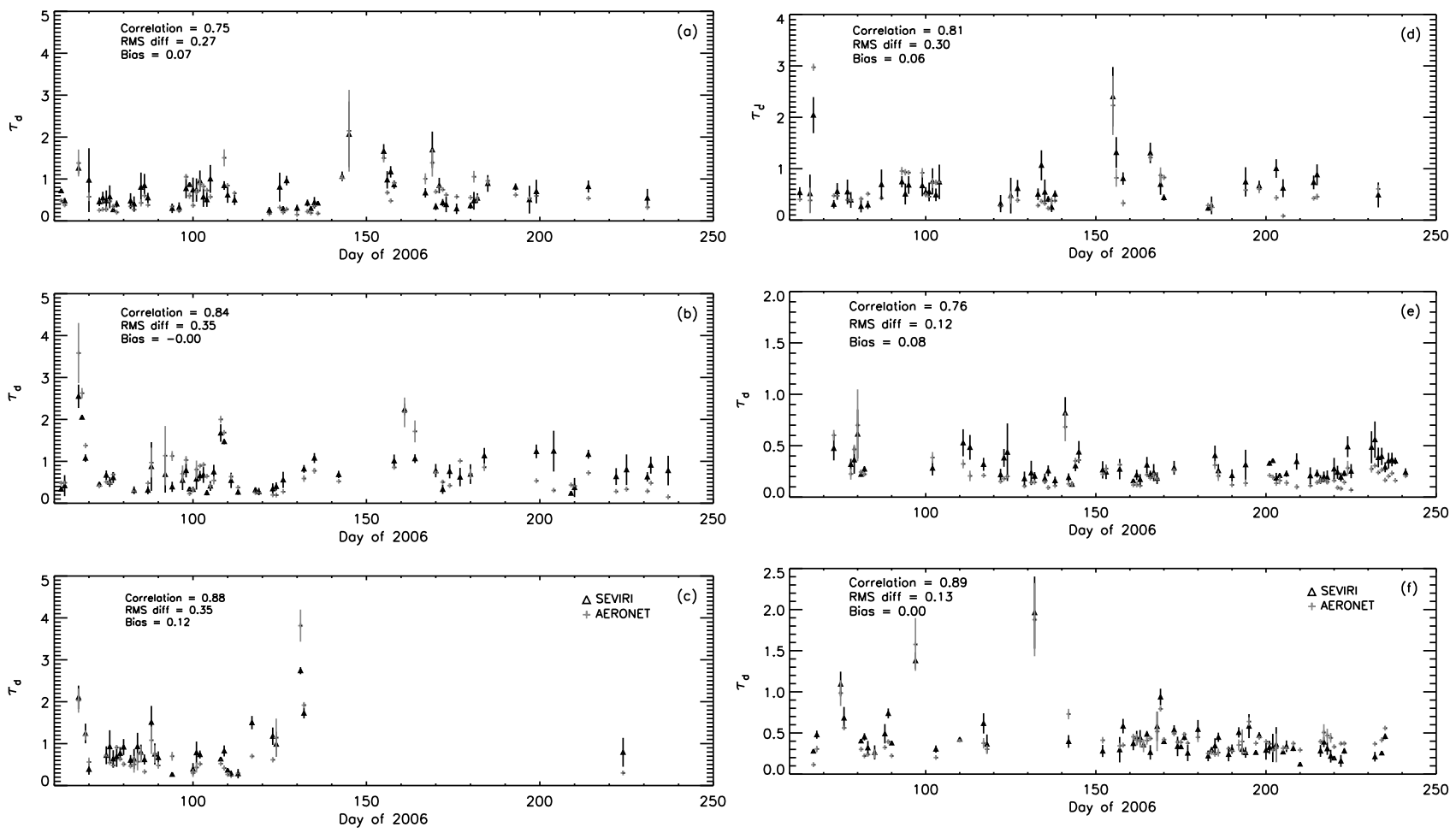

Figure 6. Daily mean $0.55 \mu \mathrm{m}$ aerosol optical thicknesses, $\tau_{\mathrm{d}}$, derived from AERONET and SEVIRI through March-August 2006 for (a) Agoufou; (b) Banizoumbou; (c) DMN Maine Soroa; (d) IER Cinzana; (e) Sede Boker; (f) Solar Village.

data sets from their original spatial resolution to provide mean values of $\tau_{055}$ for each instrument on a $0.25^{\circ}$ by $0.25^{\circ}$ fixed latitude-longitude grid. The associated standard deviation and fractional aerosol coverage in each bin is also retained. Since Terra is a Sun-synchronous polar orbiting satellite, MISR observations for a particular Earth location are made at the same local time each day. Hence on any given day, a binned MISR track is matched to the closest hourly binned SEVIRI image. In practice this means that the colocated observations presented here are always within \pm 30 min of each other. The data presented in Figures 7 and 8 show all observations matched in this way through March-May (MAM) and June-August (JJA) 2006, respectively, subdivided into $10^{\circ}$ by $10^{\circ}$ latitude-longitude bins across the study region. Two further criteria on both satellite records are imposed: first, that at least $99 \%$ of a given $0.25^{\circ}$ by $0.25^{\circ}$ bin is aerosol contaminated and, second, that the standard deviation within a bin for both instruments is less than 0.5 . These criteria ensure that a reasonable number of matches are retained, while removing the influence of obvious cloud contamination from the comparison (in practice the standard deviation test removes less than $0.5 \%$ of points). The total number of matched points in each $10^{\circ}$ by $10^{\circ}$ degree bin and the bias and RMS differences between the MISR and SEVIRI retrievals are shown in Figures 7 and 8 . The latitude band $0-10^{\circ} \mathrm{N}$ is not included in Figures 7 and 8, as a lack of matched points over this region $(<1 \%$ of total matches over the entire study region) precludes a robust analysis. The reduction of matched measurements in this band relative to the rest of the study area is likely due to smaller amounts of Saharan dust transported over this region in the months considered here [e.g., Middleton and Goudie, 2001] coupled with the increasing cloud cover due to the onset of the west African monsoon in late April [Slingo et al., 2008], and the characteristic northward progression of the intertropical convergence zone (ITCZ) in boreal spring/summer.

[25] Over the $10-40^{\circ} \mathrm{N}$ region shown in Figures 7 and 8 the pattern of agreement between MISR and SEVIRI is relatively consistent with location, with the SEVIRI based retrievals tending to be biased high relative to the MISR values (evidenced by the best fit lines), particularly for optical thicknesses in excess of $\sim 1.0$. While some of this behavior may be due to residual cloud contamination in the $\Delta \mathrm{T}_{\mathrm{B} 108} / \Delta \mathrm{T}_{\mathrm{B} 134}$ record, a similar pattern is also hinted at in comparisons of matched AERONET and MISR data over northern Africa (E. Carboni, personal communication, 2009) [see also Christopher et al., 2008, Figure 2]. For both March-May and June-August periods there is a general tendency for the level of agreement between the two records to improve as one moves northward and eastward. The latitudinal behavior could be related to the amount of biomass aerosol present within the southern part of the study region (south of $\sim 15^{\circ} \mathrm{N}$ ). Fire maps from the MODIS Rapid Response System (http://rapidfire.sci.gsfc. nasa.gov/firemaps/) show a substantial degree of fire activity persisting through March 2006 to mid-April in this area. Similarly, aircraft observations from the Dust and Biomass Experiment (DABEX) campaign based at Niamey, Niger, show typical aerosol profiles containing elevated biomass aerosol above a lower dust layer occurring during late February 2006 [Johnson et al., 2008]. If similar behavior extended to the March-April period, while the additional 

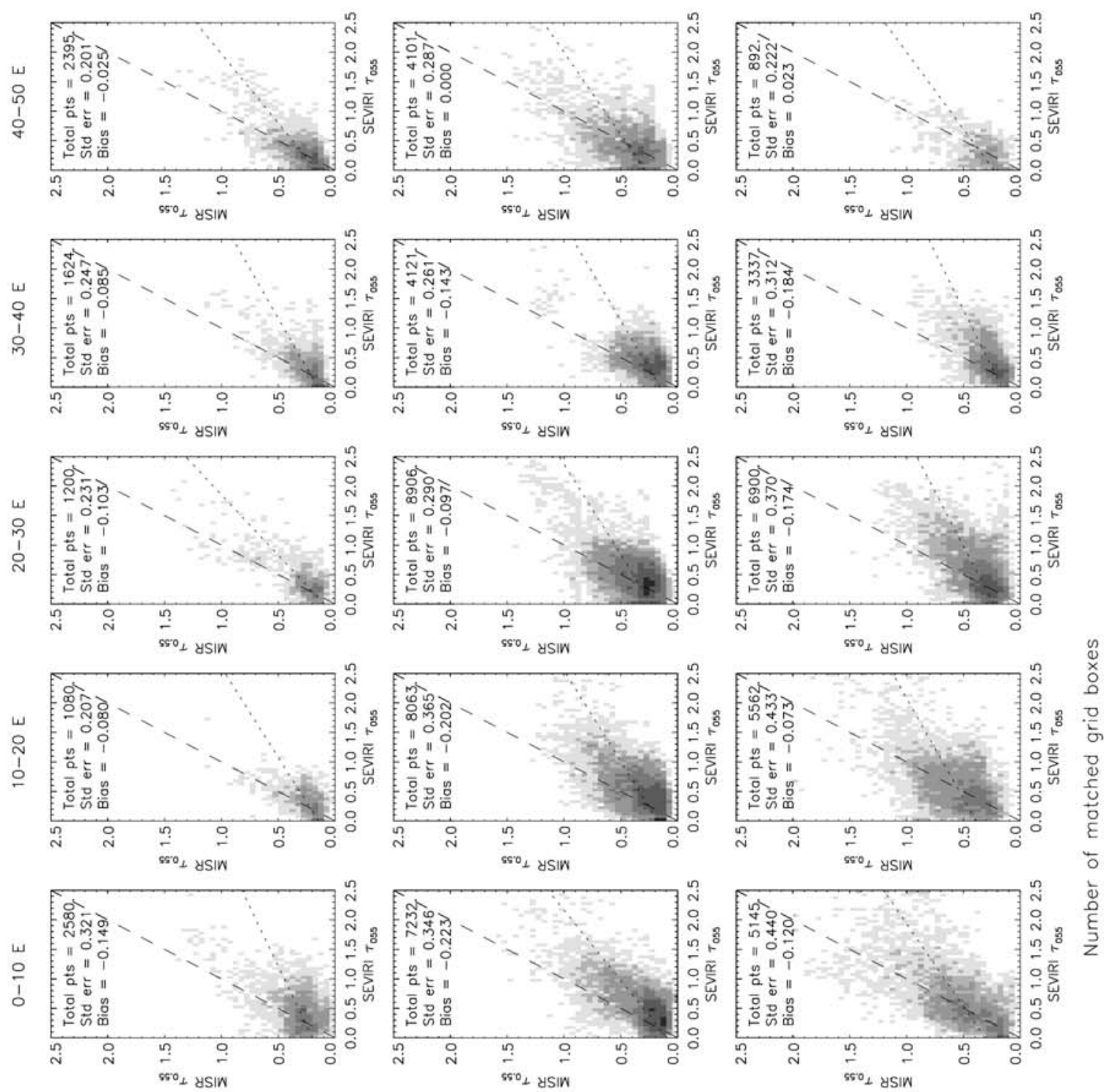

$\Xi$
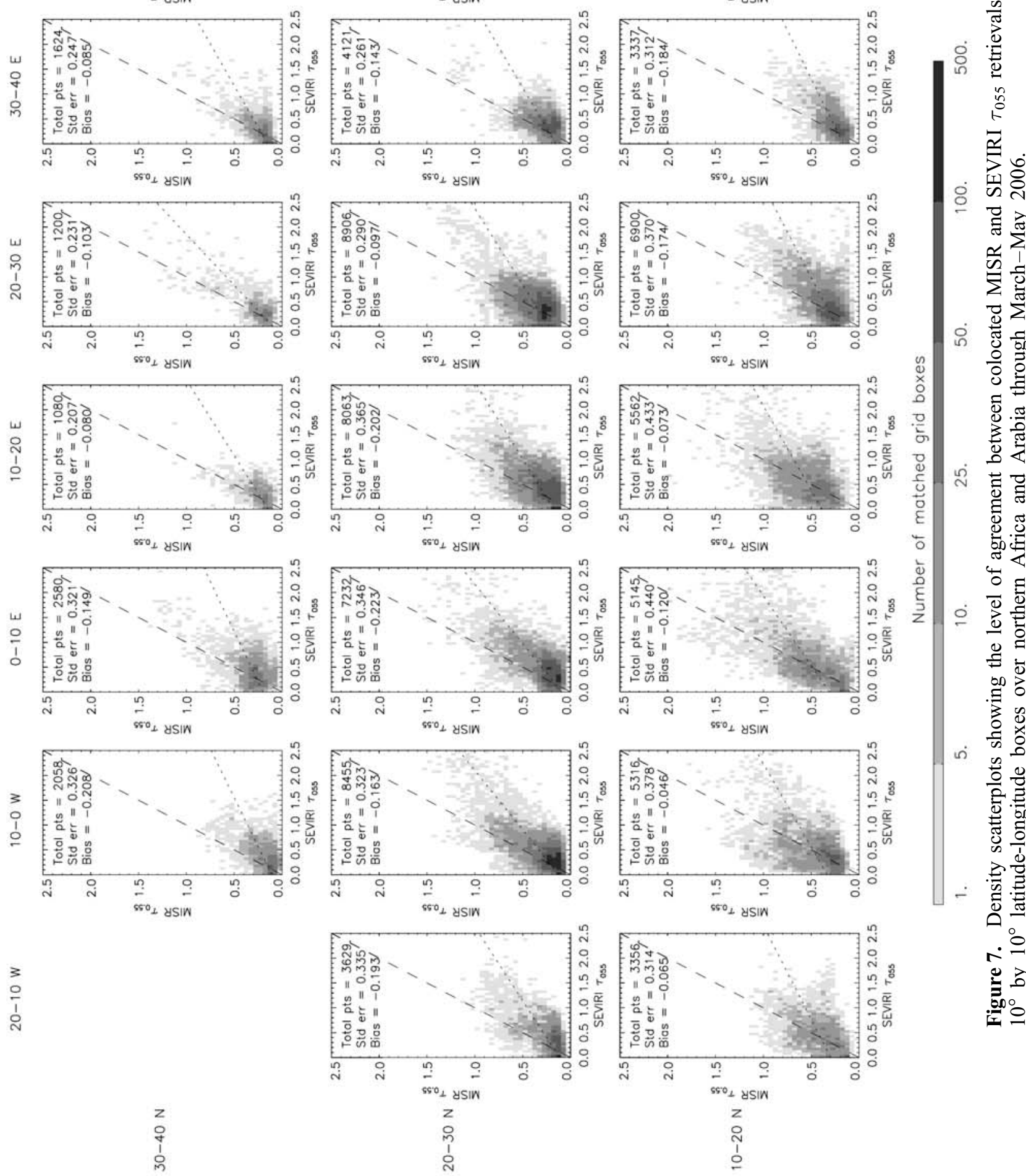

เ่

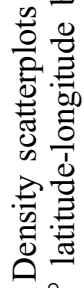

3
0
$\frac{1}{1}$
$\vdots$

드을 

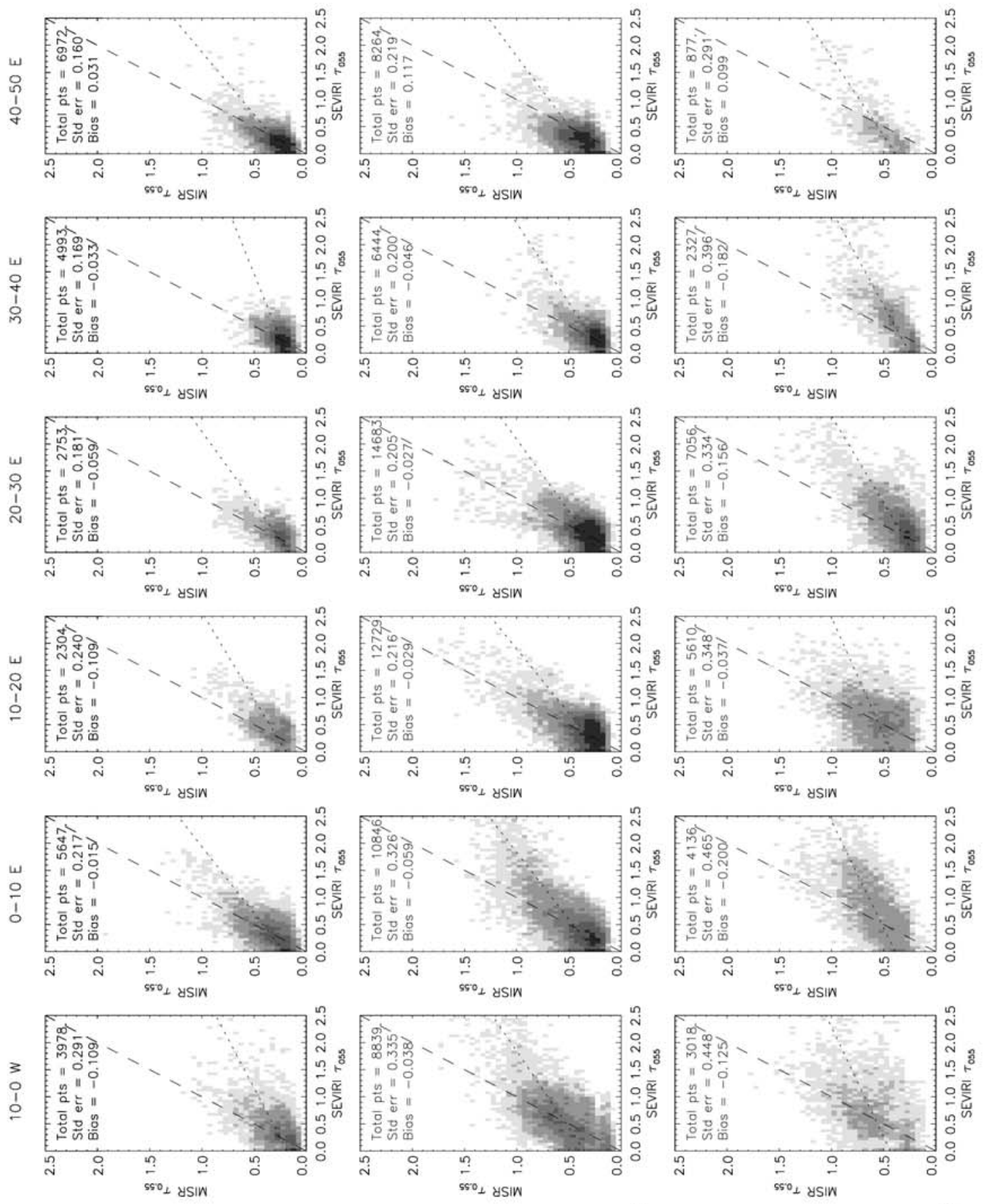

3

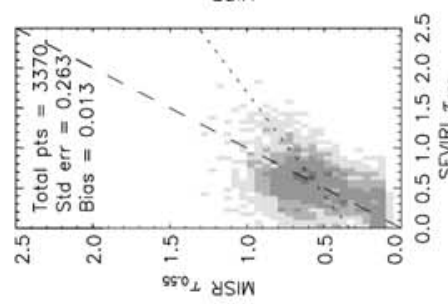

$$
\begin{aligned}
& z \\
& o \\
& y \\
& 1 \\
& 0 \\
& m
\end{aligned}
$$
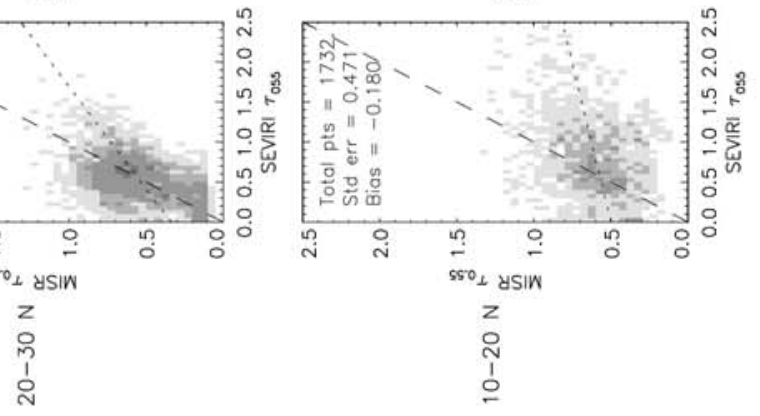
Table 4. Statistics Indicating the Level of Agreement Between Matched SEVIRI and MISR $\tau_{055}$ Retrievals Through MarchAugust 2006 Over the Entire Study Region ${ }^{\mathrm{a}}$

\begin{tabular}{lcccc}
\hline Month & $\begin{array}{c}\text { Number of } \\
\text { Matched Points }\end{array}$ & Correlation & Bias & $\begin{array}{c}\text { RMS } \\
\text { Difference }\end{array}$ \\
\hline March & 23,405 & 0.66 & -0.21 & 0.39 \\
April & 30,472 & 0.47 & -0.12 & 0.32 \\
May & 33,624 & 0.62 & -0.09 & 0.32 \\
June & 43,972 & 0.63 & -0.05 & 0.32 \\
July & 45,721 & 0.59 & -0.03 & 0.25 \\
August & 28,335 & 0.66 & -0.05 & 0.27 \\
MAM & 87,501 & 0.58 & -0.13 & 0.34 \\
JJA & 118,028 & 0.63 & -0.05 & 0.27 \\
\hline
\end{tabular}

${ }^{\mathrm{a}} \mathrm{Here}$ the bias is calculated in the sense MISR-SEVIRI.

biomass would presumably affect the values of $\tau_{055}$ obtained from MISR, its direct impact would not be seen in the SEVIRI retrievals, thus adding additional scatter to the relationships seen. Longitudinally, a similar effect may be occurring near the West African coast due to the advection and mixing of low-level sea salt aerosol layers inland.

[26] Given the seasonality of the fire activity, to assess the possibility of biomass contamination an identical analysis was performed on each individual month. Summary statistics over the whole study region, decomposed according to month, are provided in Table 4. Although there is an improvement in the level of agreement during JJA as a whole as opposed to MAM, the results do not reveal any statistically significant systematic progression in the pattern of behavior through the year over the study region. At first sight this finding appears somewhat contrary to that of Christopher et al. [2008], who performed a similar matching procedure using monthly mean MISR retrievals and Aerosol Index values derived from the Total Ozone Mapping Spectrometer/Ozone Monitoring Instruments (TOMS/OMI) over the period 2000-2006. They considered a slightly smaller geographical region covering $0-30^{\circ} \mathrm{N}$ and $20^{\circ} \mathrm{W}-40^{\circ} \mathrm{E}$, and found higher correlations between the two data sets in the June-August $(0.70-0.74)$ relative to January-March $(0.53-0.64)$ period. They attributed this difference to the typical increase seen in dust amount and layer heights in the latter relative to the former season. Although we do not expect the methodology introduced here to completely remove the effects of variation in dust layer height, it appears that the approach is sufficient to prevent any height dependence emerging as clearly. We do however note the different seasonal period and shorter record considered here.

\section{Derivation of the Cloud-Free Dust Direct Radiative Effect}

[27] To isolate the change in outgoing longwave flux at the TOA arising purely as a result of the presence of dust, a similar approach to that outlined in section 2 is applied. In this case, for each 28-day running window, nominally pristine sky flux observations for each time slot and location are identified from $\mathrm{T}_{\mathrm{B} 108 \mathrm{df}}$ and the corresponding longwave fluxes are extracted from the GERB data record and denoted

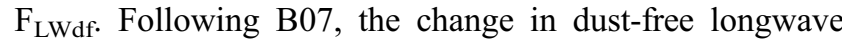
flux, $\Delta F_{L W d f}$, from this value for all other cloud-free days within the running window is estimated by accounting for the changes in $\mathrm{T}_{\text {sfc }}$, and upper (UTH) and lower tropospheric humidity (LTH) that have occurred using

$$
\Delta \mathrm{F}_{\mathrm{LWdf}}=\mathrm{b}_{1} \times \Delta \mathrm{T}_{\mathrm{sfc}}+\mathrm{b}_{2} \times \ln \left[\frac{\mathrm{LTH}}{\mathrm{LTH}_{\mathrm{df}}}\right]+\mathrm{b}_{3} \times \ln \left[\frac{\mathrm{UTH}}{\mathrm{UTH}_{\mathrm{df}}}\right]
$$

UTH and LTH are defined as the mean relative humidities from 1000 to $500 \mathrm{hPa}$ and $500-200 \mathrm{hPa}$, respectively, and $\mathrm{LTH}_{\mathrm{df}}\left(\mathrm{UTH}_{\mathrm{df}}\right)$ is the lower (upper) tropospheric humidity associated with $\mathrm{T}_{\mathrm{B} 108 \mathrm{df} \text {. }}$

[28] The cloud-free dust-only impact on the outgoing longwave flux, $\mathrm{LW}_{\mathrm{DRE}}$, is then

$$
\mathrm{LW}_{\mathrm{DRE}}=\left(\mathrm{F}_{\mathrm{LWdf}}+\Delta \mathrm{F}_{\mathrm{LWdf}}\right)-\mathrm{F}_{\mathrm{LW}}
$$

where $F_{L W}$ is the GERB longwave flux at the TOA for the given day, time slot, and location. Uncertainties in $\mathrm{LW}_{\mathrm{DRE}}$ can arise from a number of sources. Detailed regional scale comparisons of inferred GERB HR LW fluxes with colocated observations from the Clouds and the Earth's Radiant Energy System (CERES) instrument indicate agreement to within 1.3\% [Clerbaux et al., 2009]. However, for dust contaminated scenes, both simulations and a site specific study based on observations from Niamey, Niger [Bharmal et al., 2009] suggest that the conversion from radiance to flux may introduce a systematically varying bias with viewing zenith angle. This would be expected to have a positive maximum at nadir, switching to negative values at viewing zeniths greater than $\sim 52^{\circ}$. In addition, at a given viewing zenith the amount of bias would be dependent on $\tau_{055}$, peaking at dust optical depths of $\sim 2.5$. The maximum observed and simulated biases at nadir are less than $10 \mathrm{~W}$ $\mathrm{m}^{-2}$ and more typically of the order $3-5 \mathrm{Wm}^{-2}(\sim 1-2 \%)$ for $\tau_{055}$ values of less than 1 . In terms of the calculation of $\Delta \mathrm{F}_{\mathrm{LWdf}}, \mathrm{B} 07$ estimates a random uncertainty of $\sim 5 \mathrm{Wm}^{-2}$, based on the expected accuracy of the LTH, UTH, and $\mathrm{T}_{\text {sfc }}$ values. Therefore over the study region considered here, from equation (7), on any instantaneous estimate of $\mathrm{LW}_{\text {DRE }}$ we anticipate a random uncertainty of the order $10 \mathrm{~W} \mathrm{~m}^{-2}$ and a maximum possible low bias of the order $10 \mathrm{~W} \mathrm{~m}^{-2}$.

[29] Figure 9 shows $L_{\text {DRE }}$ as a function of SEVIRI derived $\tau_{055}$ over the AERONET sites highlighted in section 2.2. Also shown are the corresponding values obtained if $\Delta F_{L W d f}$ is not applied to $F_{L W d f}$ to isolate the dust impact. Although in some cases a reasonably high correlation between $\tau_{055}$ and the change in outgoing flux between dusty and nominally pristine days is seen even without applying the correction in equation (7), when it is applied a clearer relationship, with reduced scatter, is apparent in all cases. Table 5 provides an indication of the mean $\mathrm{LW}_{\mathrm{DRE}}$ and $\tau_{055}$ at each site. While the estimate of the mean $L_{\text {DRE }}$ does not take account of the possible bias in the GERB dusty fluxes noted above, simulations suggest that given the viewing angles and mean optical depths seen at the sites values at Agoufou, Banizoumbou, DMN Maine Soroa, and IER Cinzana would be reduced by at most $\sim 3 \mathrm{~W} \mathrm{~m}^{-2}$. At Saada (Solar Village) the generally smaller values of $\tau_{055}$ coupled with the viewing 


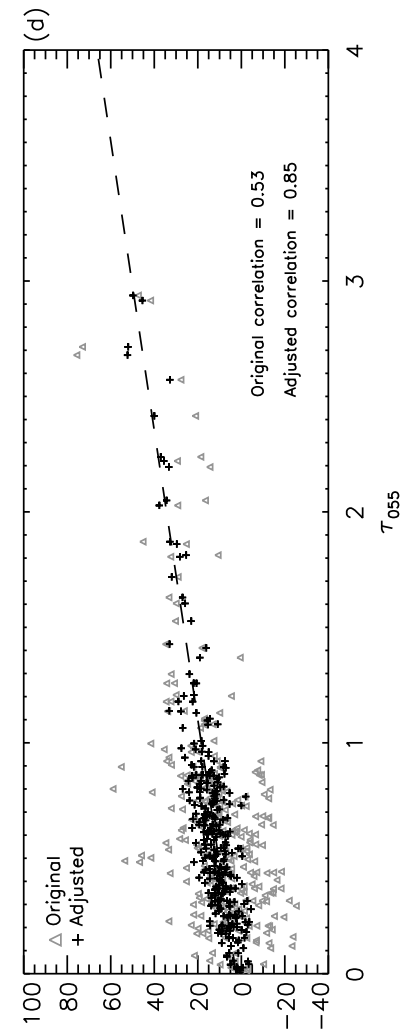

$(z-w M){ }^{380} M 7$

o

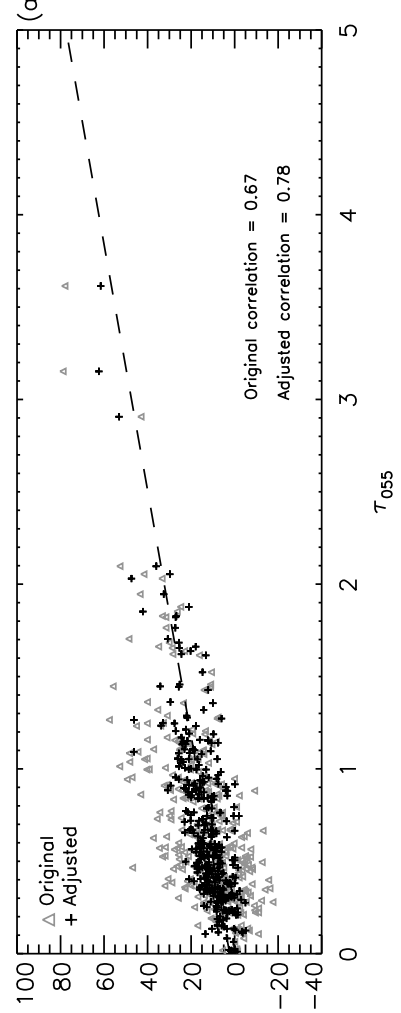

$\left.(z-w M){ }^{380} M\right\urcorner$

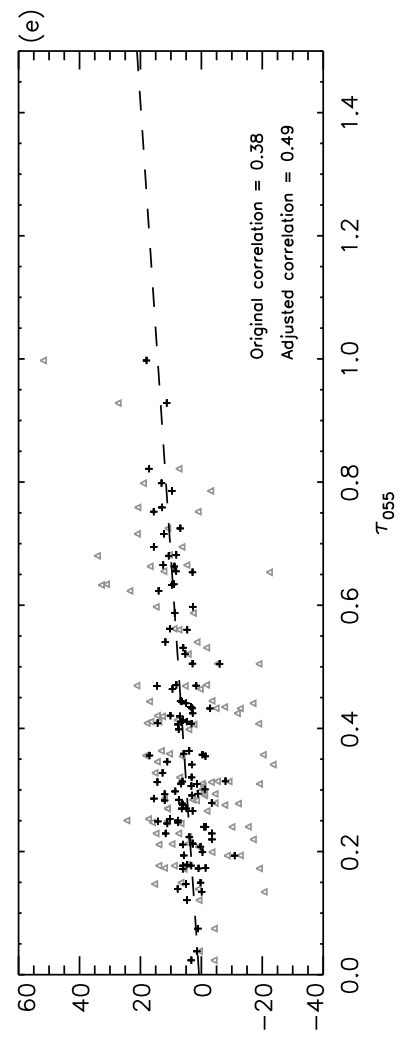

$\left.(z-m M)^{380} M\right]$

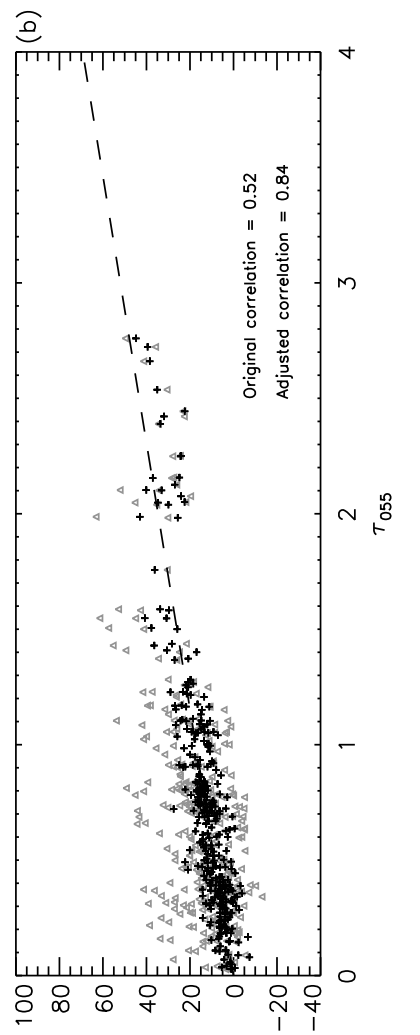

(z-w M) ${ }^{380} M 7$

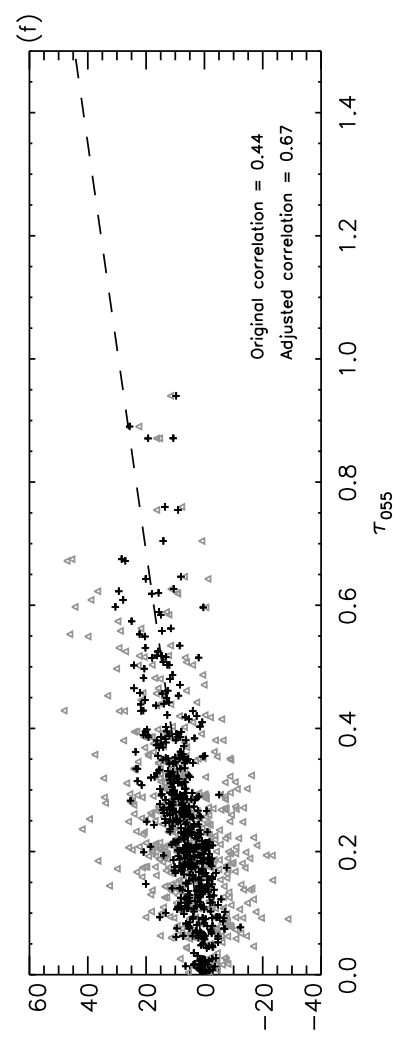

$(z-m M){ }^{380} M 7$

\section{(อ)}

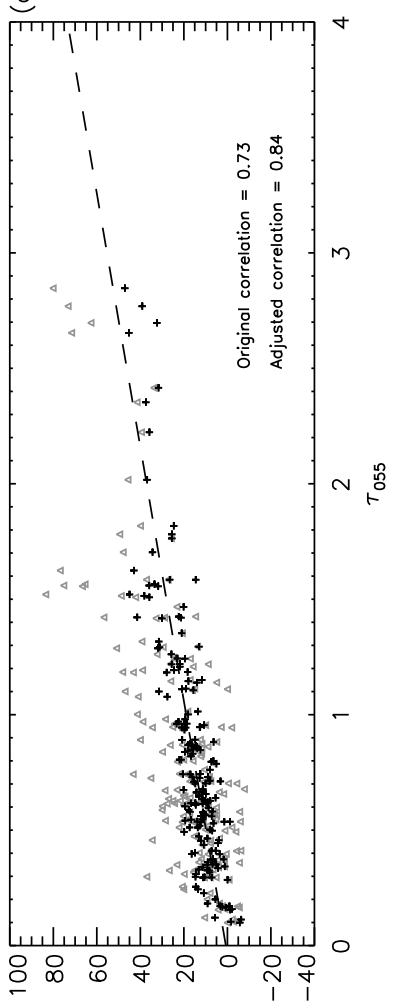

$(z-m M){ }^{380} M 7$

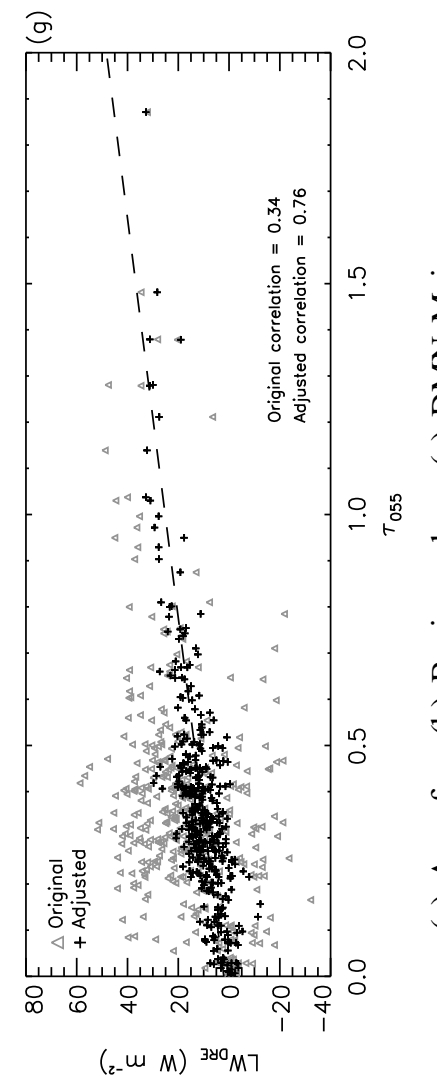

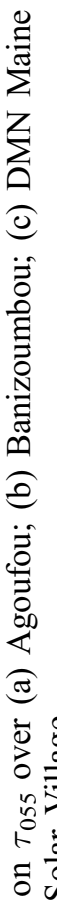

뭉

in

उ。ㅇำ

营兽

च्छ

코 ซึ์

.0.

पㅇ

8

롤

迥先

ब。

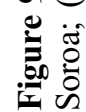


Table 5. Mean SEVIRI Derived $\tau_{055}, \mathrm{LW}_{\mathrm{DRE}}$, and Dust LW Radiative Efficiency, LW $_{\mathrm{EFF}}$ Over Selected AERONET Stations Through March-August 2006

\begin{tabular}{lcccc}
\hline & \multicolumn{3}{c}{ Mean } & \multicolumn{2}{c}{$\begin{array}{c}\text { Uncertainty } \\
\text { in LW }\end{array}$} \\
AERONET Station & $\begin{array}{c}\text { Mean } \\
\tau_{055}\end{array}$ & $\begin{array}{c}\mathrm{LW} \mathrm{m}_{\mathrm{DRE}} \\
\left(\mathrm{W} \mathrm{m}^{-2}\right)\end{array}$ & $\begin{array}{c}\left.\mathrm{LW} \mathrm{m}_{\mathrm{EFF}} \tau_{055}^{-1}\right) \\
\left(\mathrm{W} \mathrm{m}^{-2} \tau_{055}^{-1}\right)\end{array}$ \\
\hline Agoufou & 0.68 & 13 & 16 & 5 \\
Banizoumbou & 0.73 & 12 & 15 & 5 \\
DMN Maine Soroa & 0.83 & 16 & 16 & 5 \\
IER Cinzana & 0.66 & 13 & 16 & 4 \\
Saada & 0.39 & 6 & 14 & 10 \\
Sede Boker & 0.24 & 7 & 30 & 10 \\
Solar Village & 0.38 & 11 & 22 & 5 \\
\hline
\end{tabular}

${ }^{\mathrm{a}}$ The uncertainty estimates in $\mathrm{LW}_{\mathrm{EFF}}$ include the effects of likely uncertainties in the GERB fluxes themselves and in the retrieved $\tau_{055}$ values.

zenith would be expected to translate to a high (low) bias of at most $\sim 2 \mathrm{~W} \mathrm{~m}^{-2}$, while the viewing zenith at Sede Boker is such that no obvious bias would be expected.

[30] Also provided in Table 5 is an estimate of the radiative efficiency of the dust aerosol over each site, $\mathrm{LW}_{\mathrm{EFF}}$, defined as the gradient of a linear least squares fit applied to the $\tau_{055}$ and $\mathrm{LW}_{\mathrm{DRE}}$ records. Although the method of calculation of $\mathrm{LW}_{\mathrm{EFF}}$ will mitigate the effect of any possible biases in the GERB fluxes, since any biases would be expected to show some dependence on $\tau_{055}$, if present they would still influence the final value. The general effect would be to reduce the efficiency at low viewing zeniths and enhance it at higher viewing zeniths. On the basis of simulations we anticipate that the magnitude of the effect would be at most $2 \mathrm{~W} \mathrm{~m}^{-2} \tau_{055}^{-1}$. Errors in the retrieved $\tau_{055}$ values would also be expected to contribute to the uncertainty in estimates of $\mathrm{LW}_{\mathrm{EFF}}$. Given the results seen in section 2, a random error distribution with the appropriate level of root-mean-square uncertainty was applied to the $\tau_{055}$ record derived for each station and the least squares gradient recalculated. The difference between this value and the original $\mathrm{LW}_{\mathrm{EFF}}$ provides a measure of the effect of errors in $\tau_{055}$. Combining this with the effects of $\mathrm{a} \pm 10 \mathrm{~W} \mathrm{~m}^{-2}$ uncertainty in the GERB fluxes themselves and the additional $\pm 5 \mathrm{~W} \mathrm{~m}^{-2}$ uncertainty which may be expected to be introduced by the correction procedure then gives the final figure for the possible range in the $\mathrm{LW}_{\mathrm{EFF}}$ figure quoted for each site in Table 5.

[31] The $L_{\mathrm{EFF}}$ values quoted in this study for Banizoumbou are in agreement with that obtained in B07 $\left(17 \pm 5 \mathrm{~W} \mathrm{~m}^{-2} \tau_{067}^{-1}\right)$ within the quoted error estimates. While this is perhaps unsurprising given the use of essentially an extended set of the same baseline observations, the values obtained for Agoufou, Banizoumbou, DMN Maine Soroa, and IER Cinzana are also consistent with those derived by Zhang and Christopher [2003, hereafter ZC03], from instruments on the Terra satellite over their regions 1 and 2 (see Table 6). However, the strong positive value seen here over Sede Boker contrasts strongly with their finding of a negative $\mathrm{LW}_{\mathrm{EFF}}$ over the $23-32^{\circ} \mathrm{N}$, $25-35^{\circ} \mathrm{E}$ region, even given the relatively large uncertainty range associated with the value given here. In the next section we derive $\tau_{055}, \mathrm{LW}_{\mathrm{DRE}}$, and $\mathrm{LW}_{\mathrm{EFF}}$ values over the complete study area and period to establish whether the individual station findings are representative of the entire region.

[32] Given that one of the key aspects of both the method to obtain $\tau_{055}$ and the direct LW dust effect is the provision of an accurate estimate of the pristine brightness temperature and flux fields it is worth considering whether any additional bias could be introduced through the use of ECMWF operational analyses in obtaining these quantities. While atmospheric temperature and humidity fields rely on the combination of model forecasts and available observations via the assimilation procedure, the land skin surface temperature is derived purely from energy balance considerations (see http://www.ecmwf.int/research/ifsdocs/ CY28r1/index.html). Completely ignoring the effects of elevated aerosol loadings would hence tend to bias daytime skin temperatures high relative to more pristine conditions due to the scattering of incident solar radiation in the former case. For dust this would be partially, but certainly not fully, compensated by the additional trapping and reemission of longwave radiation to the surface. One might therefore expect an overestimation of both $\tau_{055}$ and $\mathrm{LW}_{\mathrm{DRE}}$ with the methodology outlined here. However, recent developments at ECMWF have seen the adoption

Table 6. Mean $\tau_{055}, \mathrm{LW}_{\mathrm{DRE}}$, and $\mathrm{LW}_{\mathrm{EFF}}$ (Defined as $\mathrm{LW}_{\mathrm{DRE}} / \tau_{055}$ ) Through March-June 2006 for Selected Regions Chosen for Consistency With Z03 and Numbered Accordingly ${ }^{\mathrm{a}}$

\begin{tabular}{|c|c|c|c|c|c|c|c|c|c|}
\hline \multirow[b]{2}{*}{ Region } & \multirow[b]{2}{*}{$\begin{array}{l}\text { Latitude } \\
\left({ }^{\circ} \mathrm{N}\right)\end{array}$} & \multirow[b]{2}{*}{$\begin{array}{c}\text { Longitude } \\
\left({ }^{\circ} \mathrm{E}\right)\end{array}$} & \multirow[b]{2}{*}{ Period } & \multicolumn{3}{|c|}{ This Study } & \multicolumn{3}{|c|}{$\mathrm{ZC} 03$} \\
\hline & & & & $\begin{array}{l}\tau_{055(\text { ALL })} \\
\tau_{055(1100)}\end{array}$ & $\begin{array}{c}\mathrm{LW}_{\mathrm{DRE}(\mathrm{ALL})} / \mathrm{LW}_{\mathrm{DRE}} \\
(1100)\left(\mathrm{W} \mathrm{m}^{-2}\right)\end{array}$ & $\begin{array}{c}\mathrm{LW}_{\mathrm{EFF}(\mathrm{ALL})} / \mathrm{LW}_{\mathrm{EFF}}(1100) \\
\left(\mathrm{W} \mathrm{m}^{-2} \tau_{055}^{-1}\right)\end{array}$ & $\tau_{055}$ & $\begin{array}{l}\mathrm{LW}_{\mathrm{DRE}} \\
\left(\mathrm{W} \mathrm{m}^{-2}\right)\end{array}$ & $\begin{array}{c}\mathrm{LW}_{\mathrm{EFF}} \\
\left(\mathrm{W} \mathrm{m}^{-2} \tau_{055}^{-1}\right)\end{array}$ \\
\hline W. Africa (1) & $16-28$ & $-16--4$ & $\begin{array}{c}\text { MAM } \\
\text { JJA }\end{array}$ & $\begin{array}{l}0.50 / 0.51 \\
0.66 / 0.67\end{array}$ & $\begin{array}{c}9 / 9 \\
11 / 11\end{array}$ & $18 / 16$ & 0.69 & 13 & 20 \\
\hline Niger/Chad (2) & $15-20$ & $5-22$ & $\begin{array}{c}\text { MAM } \\
\text { JJA }\end{array}$ & $\begin{array}{l}0.69 / 0.76 \\
0.65 / 0.72\end{array}$ & $\begin{array}{l}10 / 13 \\
11 / 13\end{array}$ & $\begin{array}{l}15 / 16 \\
16 / 18\end{array}$ & 0.75 & 15 & 21 \\
\hline Sudan (3) & $15-22$ & $22-36$ & $\begin{array}{l}\text { MAM } \\
\text { JJA }\end{array}$ & $\begin{array}{l}0.50 / 50 \\
0.50 / 53\end{array}$ & $\begin{array}{l}10 / 12 \\
12 / 14\end{array}$ & $\begin{array}{l}19 / 22 \\
21 / 23\end{array}$ & 0.66 & 9 & 19 \\
\hline Egypt/Israel (4) & $23-32$ & $25-35$ & $\begin{array}{c}\text { MAM } \\
\text { JJA }\end{array}$ & $\begin{array}{l}0.42 / 0.41 \\
0.29 / 0.31\end{array}$ & $\begin{array}{l}7 / 8 \\
7 / 8\end{array}$ & $\begin{array}{l}19 / 20 \\
25 / 27\end{array}$ & 0.51 & -1 & 1 \\
\hline N. Libya (5) & $27-33$ & $15-25$ & $\begin{array}{c}\text { MAM } \\
\text { JJA }\end{array}$ & $\begin{array}{l}0.43 / 0.44 \\
0.33 / 0.36\end{array}$ & $\begin{array}{l}8 / 9 \\
7 / 9\end{array}$ & $\begin{array}{l}18 / 21 \\
20 / 25\end{array}$ & 0.52 & 4 & 11 \\
\hline S. Libya (6) & $23-27$ & $15-25$ & $\begin{array}{c}\text { MAM } \\
\text { JJA }\end{array}$ & $\begin{array}{l}0.48 / 0.48 \\
0.33 / 0.35\end{array}$ & $\begin{array}{c}7 / 10 \\
7 / 8\end{array}$ & $\begin{array}{l}16 / 20 \\
18 / 22\end{array}$ & 0.44 & 3 & 11 \\
\hline Overall & $15-35$ & $-18--40$ & $\begin{array}{c}\text { MAM } \\
\text { JJA }\end{array}$ & $\begin{array}{l}0.46 / 0.46 \\
0.38 / 0.41\end{array}$ & $\begin{array}{l}9 / 10 \\
9 / 10\end{array}$ & $\begin{array}{l}19 / 21 \\
22 / 24\end{array}$ & 0.55 & 7 & 15 \\
\hline
\end{tabular}

a"ALL" indicates the use of all hours between 0800 and 1600 UTC to calculate the given quantities, "1100" indicates the use of only measurements taken at 1100 LT to calculate these quantities. The final three columns show the values obtained by ZC03 for September 2000. 

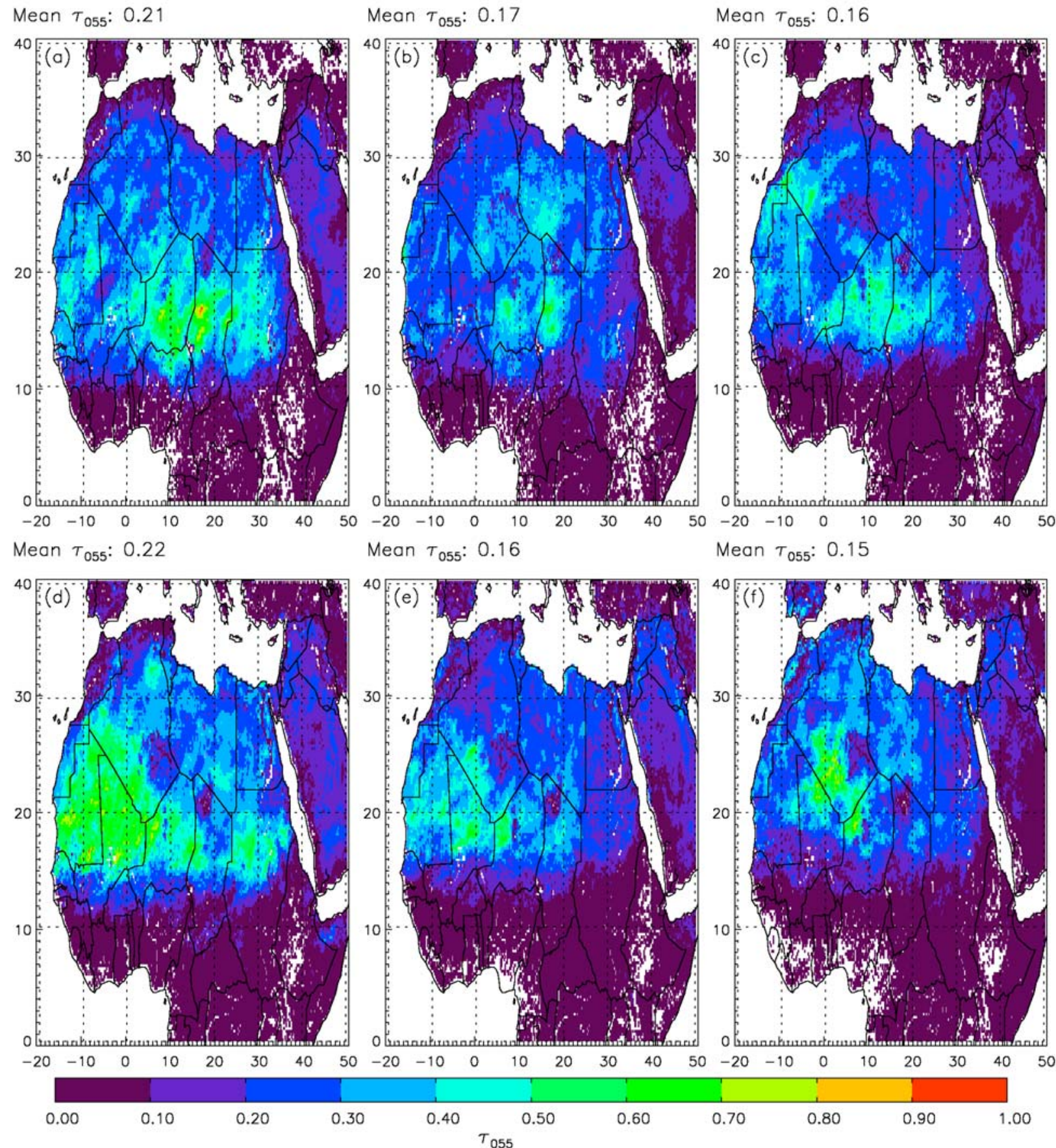

Figure 10. Monthly mean 0800-1600 UTC $\tau_{055}$ maps for (a) March; (b) April; (c) May; (d) June; (e) July; (f) August. In each case the optical thickness is weighted by the fraction of clear observations at the given location shown in Figure 12.

of an improved dust aerosol climatology in the forecast model [Tompkins et al., 2005]. While this cannot hope to capture the instantaneous dust loading at a particular time it does mean that in an average sense the impacts on skin temperature will be accounted for and hence a consistent bias in our derived quantities would not be expected. As a further test to check that there is no coherent relationship between aerosol loading and ECMWF skin-temperatures we have compared measurements of surface upwelling flux from the Atmospheric Radiation Measurement
(ARM) Mobile Facility site at Niamey, Niger with blackbody fluxes derived from the ECMWF data through 2006 Plots of the ratio of these two quantities, an effective emissivity, as a function of colocated aerosol optical depth show no correlation between the two records.

\section{Regional $\tau_{055}$ and $\mathbf{L} W_{\text {DRE }}$ Fields}

[33] To establish whether the results obtained in section 4 are typical of the study region as a whole, Figure 10 shows 


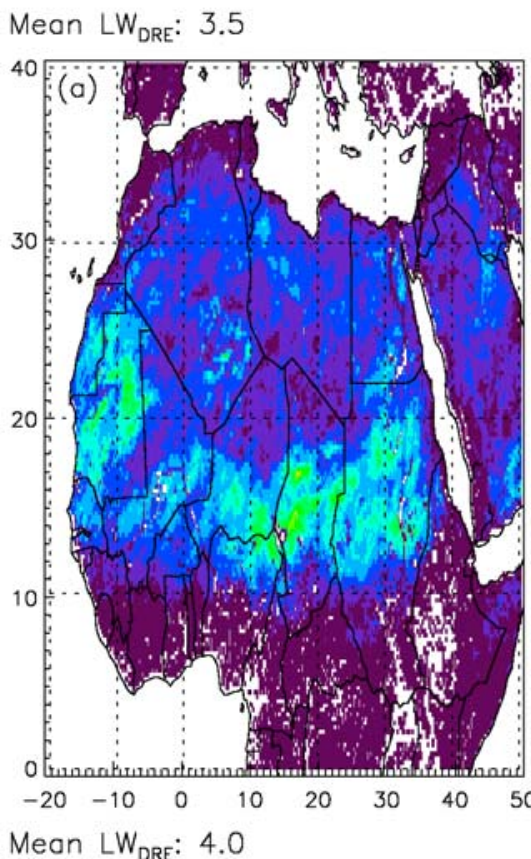

Mean LW

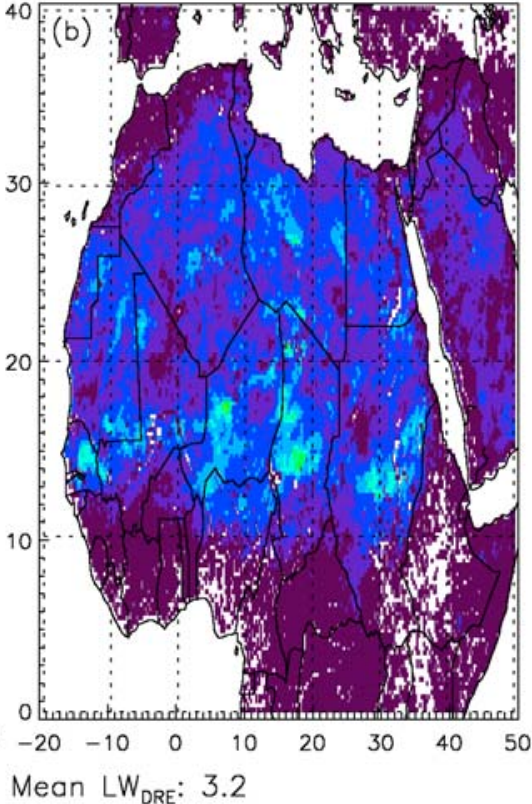

Mean LW
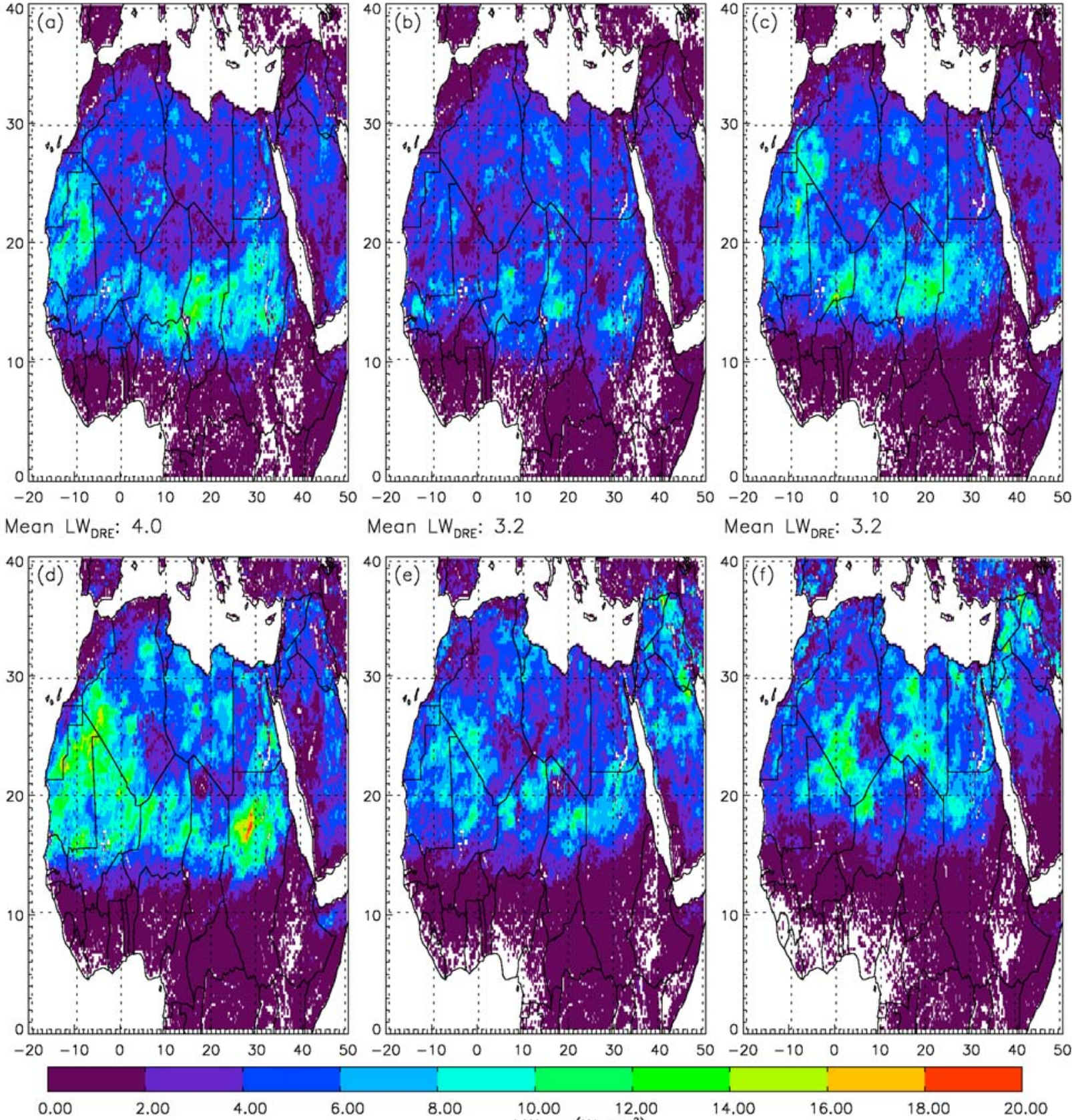

Figure 11. Monthly mean 0800-1600 UTC LW DRE maps for (a) March; (b) April; (c) May; (d) June; (e) July; (f) August. In each case the $\mathrm{LW}_{\mathrm{DRE}}$ is weighted by the fraction of clear observations at the given location shown in Figure 12.

maps of the mean 0800-1600 UTC cloud-free dust optical thickness for each month considered here. The associated $\mathrm{LW}_{\text {DRE }}$ maps are presented in Figure 11. To produce these fields the observations have been binned in an identical manner to that outlined in section 3.2.2 to produce instantaneous cloud-free values on a regular latitude-longitude grid. These instantaneous values are then averaged over all the sampled days to create mean fields for each hour. Finally, these hourly fields are averaged over time of day and weighted by the cloud-free percentage at a particular location (shown in Figure 12) to obtain the overall 08001600 UTC monthly mean values. While this approach makes the implicit assumption that the dust loading and associated direct effect is zero under cloudy conditions observed during these time slots, it does serve to correctly highlight the relative importance of the different areas within the region. White values over continental regions indicate either persistent cloud through the month or the presence of large lakes or rivers. 

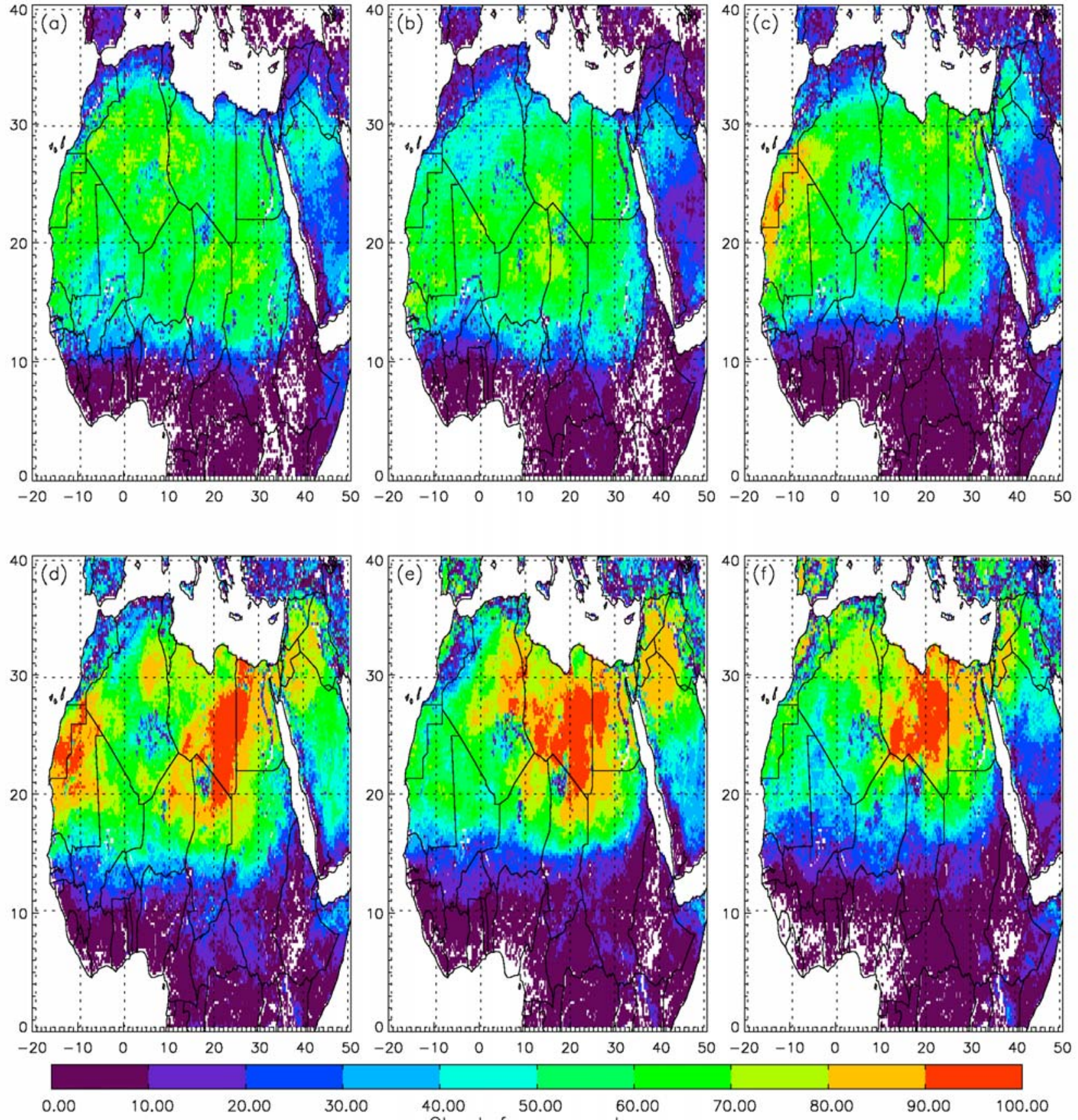

Figure 12. Percentage of cloud-free observations at each location over the study region for (a) March; (b) April; (c) May; (d) June; (e) July; (f) August.

[34] Looking at Figures 10 and 11, as might be expected if changes in the atmospheric background state have been properly accounted for, the regions of largest $\mathrm{LW}_{\mathrm{DRE}}$ are generally coincident with the highest values of $\tau_{055}$. The migration of the ITCZ and onset of the West African monsoon through boreal spring and summer shifts the boundary between consistently elevated $\left(\tau_{055}>0.15\right)$ and background dust levels northward through the period considered from $\sim 10$ to $15^{\circ} \mathrm{N}$. Within this region, the pattern of dust loading (and hence $\mathrm{LW}_{\mathrm{DRE}}$ ) shows month-to-month variability which would appear broadly consistent with previous work using long-term observations from TOMS to identify key source regions over northern Africa and Arabia [Engelstaedter et al., 2006]. Elevated $\tau_{055}$ values are seen over the Bodélé depression throughout MAM before decaying slightly in JJA. Conversely, optical thicknesses over northwestern and western Africa (Mauritania, Mali, and Algeria) show a marked increase from the spring to summer months. Over the Nubian desert (centered at $\sim 21^{\circ} \mathrm{N}, 33^{\circ} \mathrm{E}$ ) and eastern Sudan optical thicknesses peak during June. Reassuringly, given their use of the three SEVIRI window channels at 8.7, 10.8, and 12.0 microns, 
Mean LW ${ }_{\text {EFF }}$ : 16.7

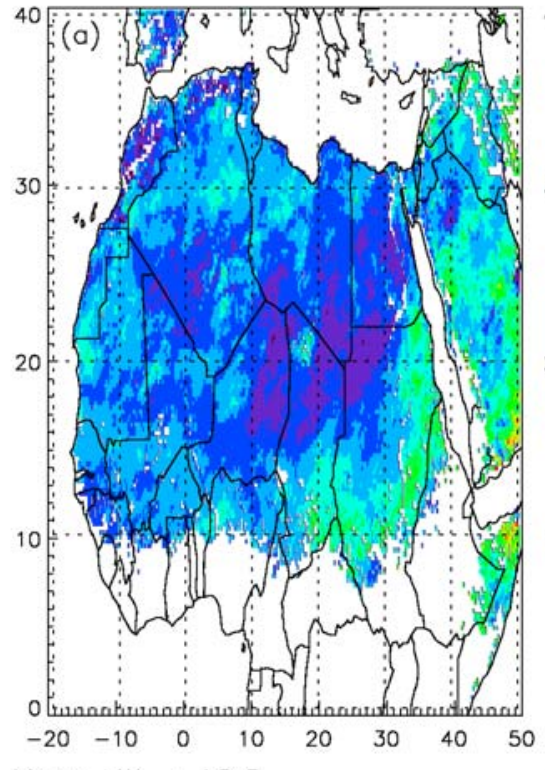

Mean LW EFF: 18.8

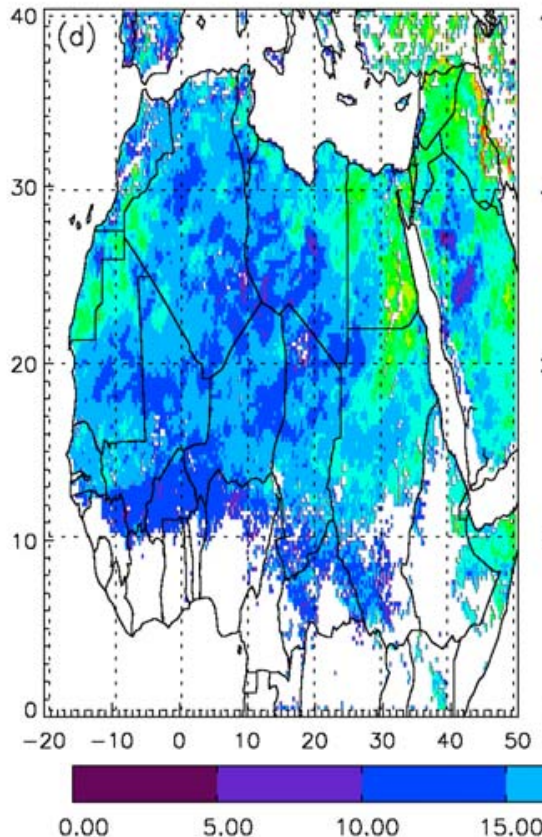

Mean LW ${ }_{\text {EFF: }} 19.0$

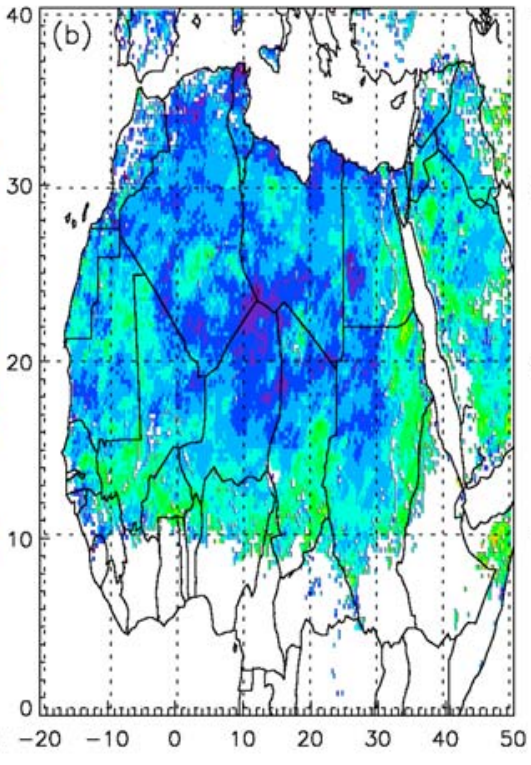

Mean LW

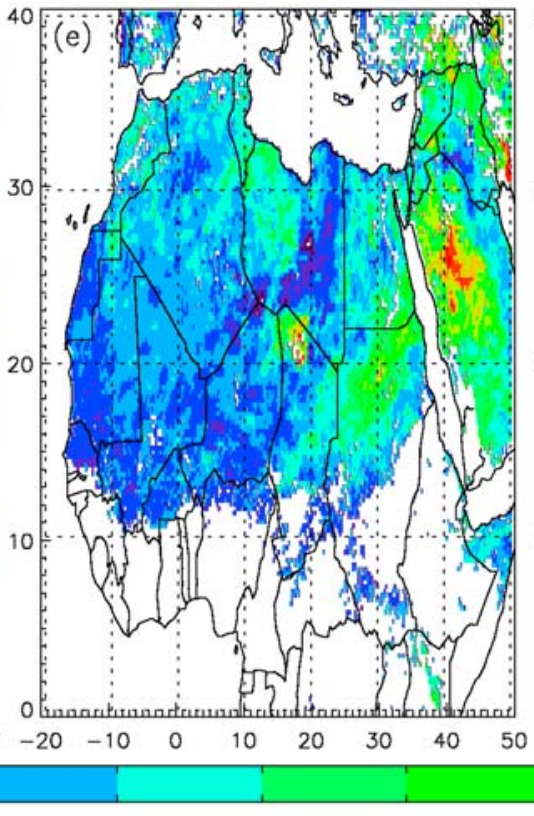

Mean $L W_{E F F}: 20.3$

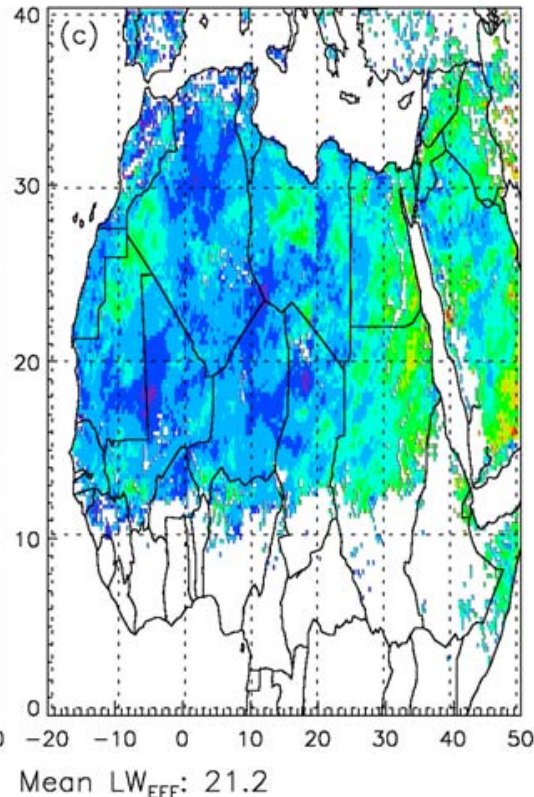

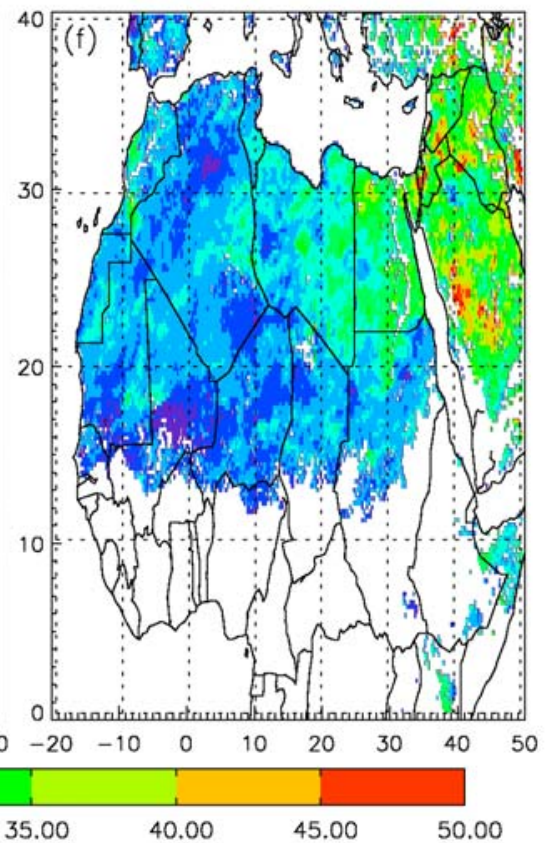

Figure 13. Monthly mean 0800-1600 UTC maps of the LW dust radiative forcing efficiency, $\mathrm{LW}_{\mathrm{EFF}}$, for (a) March; (b) April; (c) May; (d) June; (e) July; (f) August. See text for details of the $\mathrm{LW}_{\mathrm{EFF}}$ calculation process.

the results here also show good agreement with the dust source maps generated by Schepanski et al. [2007] for 2006, particularly in terms of the locations of maximum dust loading/source activation (compare for example their Figure $2 \mathrm{a}$ and Figure 10e here). Considering the area as a whole, the mean values of both $\tau_{055}$ and $\mathrm{LW}_{\mathrm{DRE}}$ are remarkably consistent from month to month.

[35] Corresponding monthly mean distributions of $\mathrm{LW}_{\mathrm{EFF}}$ are presented in Figure 13. Here, as in section 4, $\mathrm{LW}_{\mathrm{EFF}}$ is calculated as the gradient of the best linear least squares fit of $\mathrm{LW}_{\mathrm{DRE}}$ versus $\tau_{055}$. Two caveats are also applied before the fit is made: first, a given grid box must be classified as dusty for at least $10 \%$ of the time period considered and second, the range of $\tau_{055}$ encompassed must be greater than 0.5 . White land values in Figure 13 indicate where these criteria were not met while the uncertainty in $\mathrm{LW}_{\mathrm{EFF}}$, defined as the uncertainty associated with the gradient of the linear fit, is shown in Figure 14. For the summer months, over the majority of western Africa the $\mathrm{LW}_{\mathrm{EFF}}$ is relatively homogeneous with values typically between $\sim 10$ 
Mean Uncertainty: 4.8

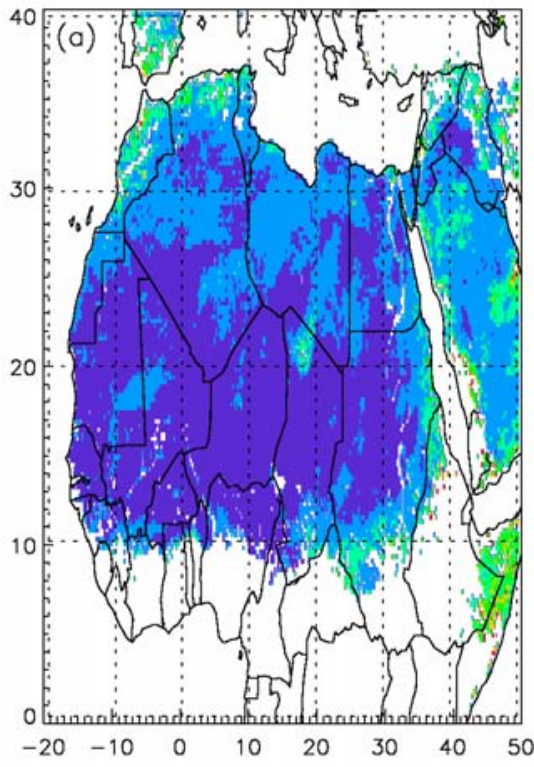

Mean Uncertainty: 4.8

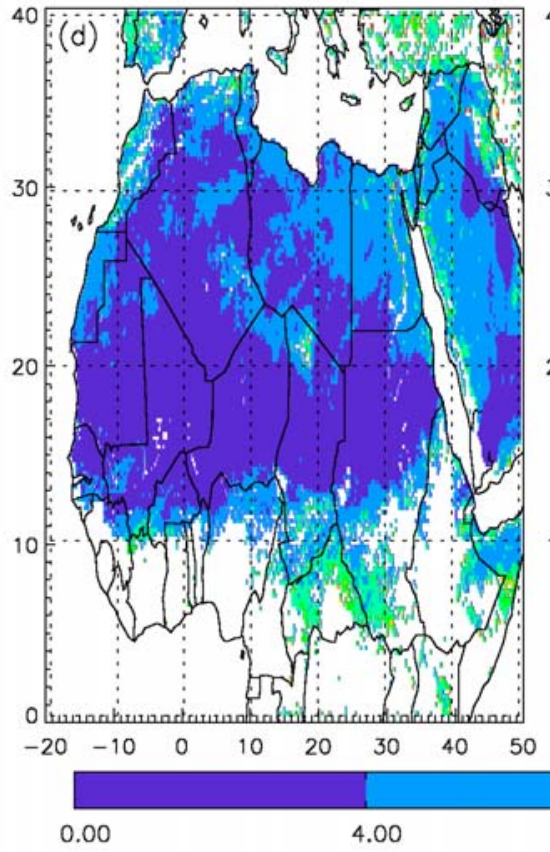

Mean Uncertainty: 5.9

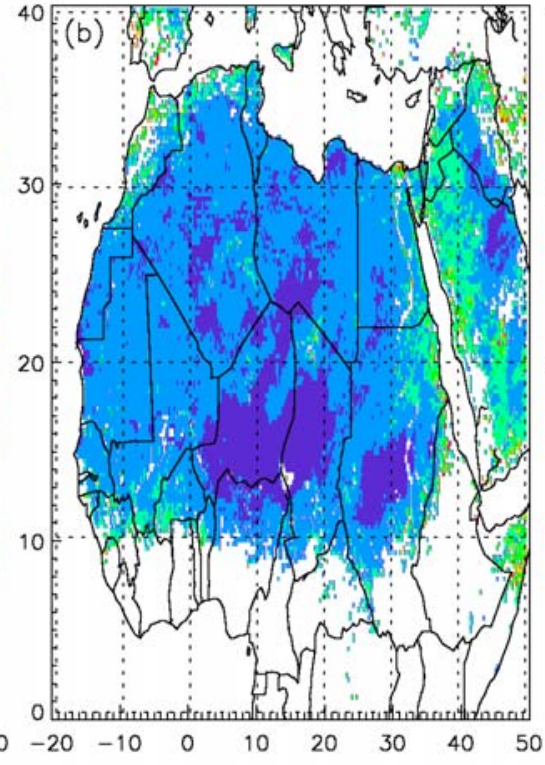

Mean Uncertainty: 5.8
Mean Uncertainty: 5.4

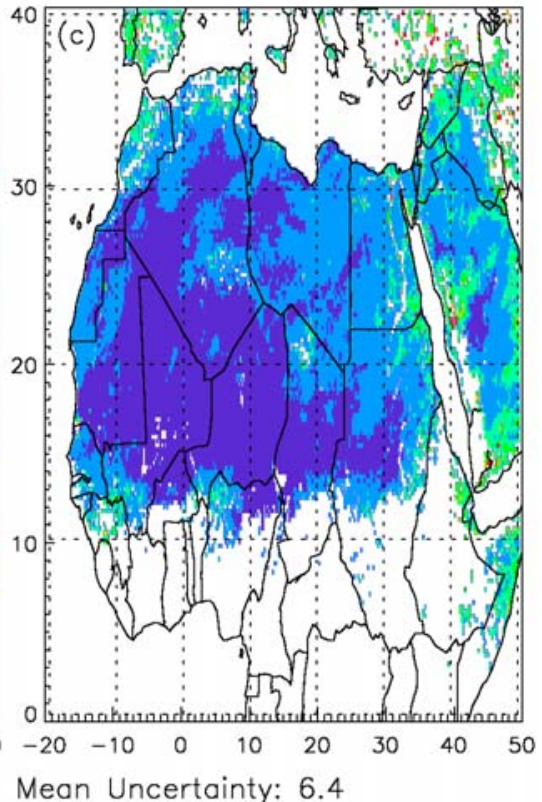

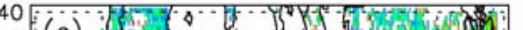
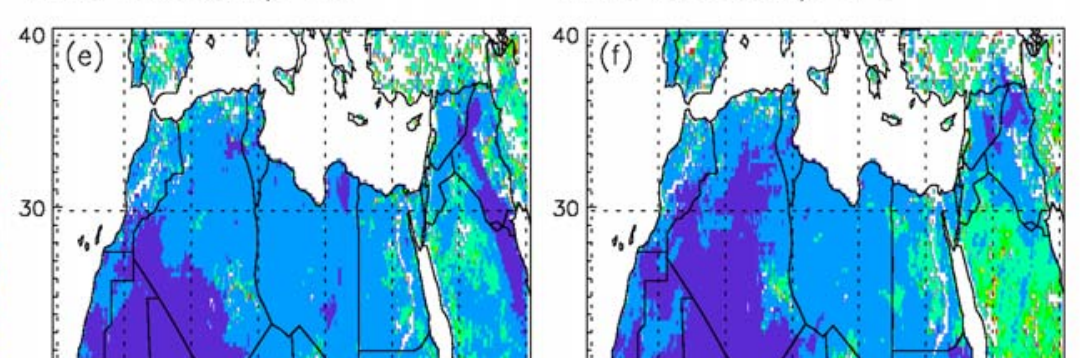

;
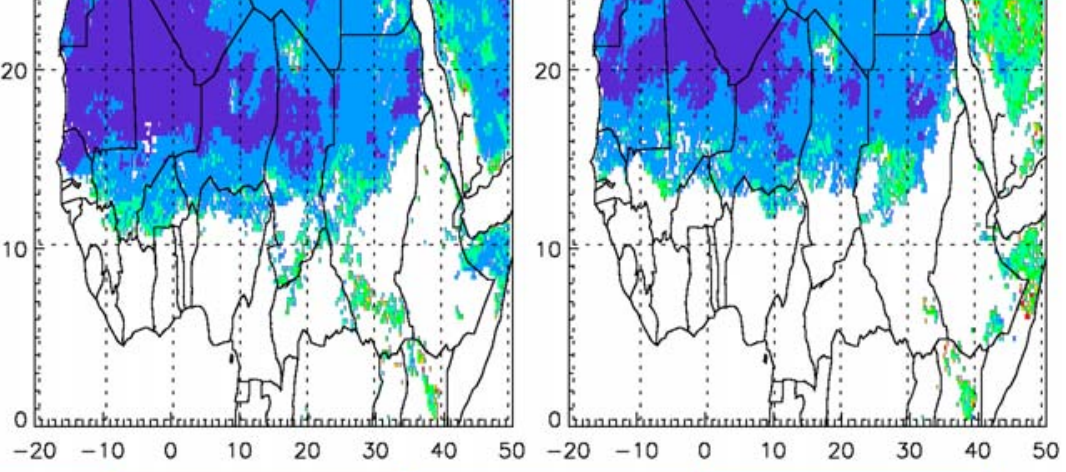

$\begin{array}{llllllll}-20 & -10 & 0 & 10 & 20 & 30 & 40 & 50\end{array}$

$-20-10$

Uncertainty in $\mathrm{LW}_{\mathrm{EFF}}{ }^{12.00}\left(\mathrm{~W} \mathrm{~m}^{-2} \tau_{055^{-1}}{ }^{-1}\right)$

16.00

20.00

Figure 14. Monthly mean 0800-1600 UTC maps of the uncertainty in $\mathrm{LW}_{\mathrm{EFF}}$ for (a) March; (b) April; (c) May; (d) June; (e) July; (f) August.

and $20 \mathrm{~W} \mathrm{~m}^{-2} \tau_{055}^{-1}$ and associated uncertainties of less than $\sim 8 \mathrm{~W} \mathrm{~m}^{-2} \tau_{055}^{-1}$. In the spring, values over the same region show rather more variation with location but still retain similar uncertainty characteristics. However, over the entire region and time period considered, the largest African efficiencies are located over the Nubian desert in May, June, and July. Elevated $\mathrm{LW}_{\mathrm{EFF}}$ values can also be found over the Great Sand Sea on the Libyan-Egyptian border from May onward and over the Nefud desert in northern Saudi Arabia in July and August, although over this latter region the associated uncertainties in the $\mathrm{LW}_{\mathrm{EFF}}$ values are larger, particularly in August. In the context of the Sede Boker station results highlighted in section 4 it is also interesting to note consistently high efficiencies over the Negev desert from May through August.

[36] To check the consistency of the results presented here with those of $\mathrm{ZC} 03$, Table 6 presents mean values of $\tau_{055}, \mathrm{LW}_{\mathrm{DRE}}$, and $\mathrm{LW}_{\mathrm{EFF}}$ for each of the seven regions identified in their study over the 6 month period considered here. In this case the values are not weighted by percentage dust occurrence so are indicative of the mean instantaneous cloud-free dust loading and impact. Before discussing the 
results we note that the study of ZC03 focused on September 2000, and, although a sensitivity analysis of the effects of precipitable water vapor, surface temperature, and aerosol height was performed, the impact of changes in these quantities was not explicitly accounted for in their estimation of $\mathrm{LW}_{\mathrm{DRE}}$ and hence $\mathrm{LW}_{\mathrm{EFF}}$.

[37] As expected from Figures 10 and 11, over West Africa (region 1) values of $\tau_{055}$ and $\mathrm{LW}_{\mathrm{DRE}}$ derived from SEVIRI and GERB show a marked increase from spring to summer. A smaller spring to summer increase in the latter quantity is also seen over regions 2 and 3. Conversely, further east over Egypt, Israel, and Libya larger $\tau_{055}$ values are seen in the spring before reducing in the summer months. The corresponding $\mathrm{LW}_{\mathrm{DRE}}$ values either show a small reduction or remain constant with season. Because $\mathrm{LW}_{\mathrm{EFF}}$ effectively involves the ratio of $\mathrm{LW}_{\mathrm{DRE}}$ and $\tau_{055}$ its seasonal variation in each region tends to be in the opposite direction to that of the latter two quantities.

[38] Comparing the results obtained here with those presented in $\mathrm{ZC03}$, in general the pattern of behavior between the different regions is similar, although this study tends to show a reduced dependence of the various quantities on location. In absolute terms, for regions $1-3$ the absolute level of agreement is relatively good, especially when considering the different time periods and instrumentation used to make the two sets of estimates. However, over the remaining regions $\tau_{055}$ derived from SEVIRI tends to be slightly lower while the corresponding $\mathrm{LW}_{\mathrm{DRE}}$ estimates from GERB tend to be larger than those seen from the Terra instruments in ZC03. Consequently, the estimates of $\mathrm{LW}_{\mathrm{EFF}}$ are also substantially higher in this study, with the highest efficiency seen in region 4 . This is completely contrary to the results of $\mathrm{ZCO} 3$ who see the lowest values of both $\mathrm{LW}_{\mathrm{DRE}}$ and $\mathrm{LW}_{\mathrm{EFF}}$ in this region. Long-term measurements over the Negev desert [Offer and Goossens, 2004] suggest that vertical fluxes and mixing of dust are highest in boreal spring/early summer and at a minimum in autumn. Given that dust height will strongly affect the $\mathrm{LW}_{\mathrm{DRE}}$ this may go some way to explaining the enhanced values seen over the months considered here relative to $\mathrm{ZC} 03$.

[39] A further factor that could influence the level of agreement seen between this study and ZC03 is the difference in daily sampling between the two instruments. To establish whether this is likely to constitute a significant effect, the SEVIRI/GERB observations were subsampled to only retain points close to a local time of $1100 \mathrm{LT}$, in an attempt to mimic the Terra nominal equator crossing time of $1030 \mathrm{LT}$. The resulting values of $\tau_{055}, \mathrm{LW}_{\mathrm{DRE}}$, and $\mathrm{LW}_{\mathrm{EFF}}$ are also provided in Table 6. Generally, all regions show slightly higher values of $\tau_{055}$ and $\mathrm{LW}_{\mathrm{DRE}}$ which compensate to translate into essentially unchanged values of $\mathrm{LW}_{\mathrm{EFF}}$. The increases in the former quantities are relatively small and certainly within the uncertainty of each measure. This suggests that, considering only cloud-free sunlit conditions, Saharan dust events are sporadic enough in nature for $\tau_{055}$ and $\mathrm{LW}_{\mathrm{DRE}}$ estimates derived from instruments in low earth orbit to give a good representation of the overall mean state.

\section{Discussion and Conclusions}

[40] A methodology was recently developed to simultaneously estimate dust optical thickness and the associated cloud-free longwave dust direct radiative effect, $\mathrm{LW}_{\mathrm{DRE}}$, over North Africa and Arabia using observations from the SEVIRI and GERB instruments flying on the geostationary Meteosat second generation satellite series. While the technique essentially built on the approach used to derive the climatological once-daily Infrared Difference Dust Index (IDDI) [Legrand et al., 2001], it was designed to specifically account for the impact of a changing atmospheric background state. Originally tested over one Sahelian ground-based site and at 1200 UTC only (B07), in this paper we have extended the work to cover a wider range of observation times throughout the day and the full North African and Arabian region to assess whether the technique can be applied more generally.

[41] In order to quantify the likely uncertainty in dust loading estimates obtained using the method a number of theoretical simulations of the expected relationship between the dust signal seen in the $10.8 \mu \mathrm{m}$ channel, $\Delta \mathrm{T}_{\mathrm{B} 108}$, and the corresponding visible optical thickness at $0.55 \mu \mathrm{m}, \tau_{055}$, were performed. These show, as expected, a marked dependency on the vertical location of the dust layer and the dust mineralogy, with a much smaller sensitivity to variations in surface emissivity.

[42] For a given dust representation, the amount of scatter caused by the variation in dust layer altitude precludes the use of the single $\Delta \mathrm{T}_{\mathrm{B} 108}$ versus $\tau_{055}$ relationship introduced in the previous work. However, stratifying the simulations according to the contrast between surface skin temperature and the mean temperature of the dust layer allows a relatively clear exponential dependency of $\Delta \mathrm{T}_{\mathrm{B} 108}$ on $\tau_{055}$ to emerge for each temperature difference bin. By introducing observations from an additional SEVIRI channel at $13.4 \mu \mathrm{m}$, effectively sounding the lower troposphere, a proxy measure of the dust layer/surface skin temperature contrast can be obtained. This extra information is encapsulated in the ratio $\Delta \mathrm{T}_{\mathrm{B} 108} / \Delta \mathrm{T}_{\mathrm{B} 134}$, and the relationship between this quantity and $\tau_{055}$ is sufficiently well defined to allow optical depths to be obtained over the range of dust heights inferred from satellite-borne LIDAR. The precise nature of the relationship is dependent on the dust model employed, although the four representations employed here essentially collapse into two different regimes and can be considered to be either "Volz" [Volz, 1973] or "Fouquart" [Fouquart et al., 1987] like. Assuming that the simulations encompass the likely range of atmospheric conditions and dust loadings and that one individual dust model is sufficient to represent all dust types, the highest possible accuracy that could be expected in an estimate of $\tau_{055}$ ranges from $\sim 0.24$ to 0.37 dependent on viewing angle. Incorporating the additional errors that would be expected to be introduced by an imperfect knowledge of the pristine sky brightness temperature on a given day would increase the associated uncertainty by $\sim 0.1$.

[43] Comparisons of $\Delta \mathrm{T}_{\mathrm{B} 108}$ and $\Delta \mathrm{T}_{\mathrm{B} 108} / \Delta \mathrm{T}_{\mathrm{B} 134}$ observations derived from SEVIRI with colocated AERONET measurements from Sahelian, Arabian, and north African sites show a pattern of behavior which is consistent with that expected from the simulations. At all UTC times considered the correction to account for changes in the background atmospheric state reduces the scatter seen in the $\tau_{055}$ versus $\Delta \mathrm{T}_{\mathrm{B} 108}$ relationship. The scatterplots also suggest that the Volz-like representation is more capable 
of capturing the observed relationship than that due to Fouquart, at least for the spatial region and time period covered by this study. This relationship appears fairly robust to changes in time of day, although there is the possibility that a reducing lapse rate toward local dawn and dusk may result in a reduction in the gradient of $\Delta \mathrm{T}_{\mathrm{B} 108}$ with increasing $\tau_{055}$. The effect of this reduction is less marked in the $\Delta \mathrm{T}_{\mathrm{B} 108} / \Delta \mathrm{T}_{\mathrm{B} 134}$ analyses giving confidence in the ability of the modified approach to compensate for changes in the effective temperature of the dust layer. Applying the appropriate Volz fit to the colocated $\Delta \mathrm{T}_{\mathrm{B} 108}$ values and constructing daily mean time series shows that the approach is also capable of capturing the temporal behavior at the individual AERONET sites. Linear correlations range from 0.75 to 0.89 dependent on site, with associated root-meansquare (rms) differences that are typically similar to or less than those expected theoretically. Further comparisons with matched retrievals from MISR again indicate a relatively consistent relationship, this time with location across the study region. While the limited number of coincident observations over the southern part of the region (latitudes between 0 and $10^{\circ} \mathrm{N}$ ) preclude quantitative inferences being made, further north $\left(10-40^{\circ} \mathrm{N}\right)$ the level of correlation between the two records is typically around 0.6 , with RMS differences that are again close to the expected theoretical accuracy of the SEVIRI retrievals. The level of agreement does show a limited dependence on season, with a slightly higher correlation and reduced RMS in boreal summer relative to spring. However, decomposing by month, the discrepancy appears more due to a rather poorer level of agreement in April relative to the remaining months than a clearly systematic trend. Future analysis of additional years in the SEVIRI record is required to infer whether a definitive seasonal pattern of behavior is present. We do however note that similar to previous studies, the retrievals from SEVIRI tend to be biased high relative to MISR as $\tau_{055}$ increases [e.g., Christopher et al., 2008; Jiang et al., 2007].

[44] While there are a number of alternative aerosol products that can be used to validate the SEVIRI $\tau_{055}$ retrievals, previous observational estimates of the $L_{\text {DRE }}$ over the north African region are rather limited both in time and space [Hsu et al., 2000; ZC03]. Nevertheless, values of the cloud-free dust $\mathrm{LW}_{\mathrm{DRE}}$ derived here over the seven AERONET sites used throughout this study show that accounting for the effects of atmospheric humidity and surface temperature permits a much clearer relationship to be obtained between dust loading and its radiative impact. Comparisons with ZC03 show generally good agreement over the western and southern part of the study region in terms of both dust loading, $\mathrm{LW}_{\mathrm{DRE}}$ and the associated dust radiative efficiency. However, moving toward the northeastern side of the region the level of agreement reduces substantially, particularly over Egypt, Israel, and Libya. In these areas we see substantially higher values of $L W_{D R E}$ than those reported by ZC03, which, combined with smaller estimates of $\tau_{055}$, combine to inflate the radiative efficiency values. Conversely, by eye comparisons with the results of Hsu et al. [2000] suggest the $\mathrm{LW}_{\mathrm{DRE}}$ values obtained in their study for February and July 1985 are generally higher than those generated here, particularly over Libya. Although both of these studies discuss the influence of changes in the atmospheric state on the dust $\mathrm{LW}_{\mathrm{DRE}}$ neither explicitly account for them in their estimates, which may go some way to explaining the discrepancies seen. Similarly, intraseasonal and interannual variability would be expected to contribute to differences in the estimates obtained between ours and both previous studies. Again, future efforts to extend the SEVIRI/GERB based record will help to establish the levels of these temporal variations.

[45] In summary, we believe we have shown that the technique presented here provides a relatively simple, reliable approach that can be used to routinely generate dust optical thickness and $\mathrm{LW}_{\mathrm{DRE}}$ estimates from SEVIRI and GERB over the daytime period to the accuracy levels described above. The approach is designed to be applied in near real time and so could be incorporated in the GERB processing scheme rather than being run "off-line," as has been done here. Future work will seek to investigate whether a similar methodology can be used through the full diurnal cycle in order to assess the importance of the dust direct effect in modifying the evolution of the subsequent atmospheric conditions.

[46] Acknowledgments. Thanks to colleagues at the Royal Meteorological Institute Belgium for providing the GERB HR flux data and NWC SAF software, to the PIs and staff of the highlighted AERONET sites, to ECMWF for supplying operational analysis fields, to the ASDC for providing access to the MISR data, and to three anonymous reviewers for their helpful comments. HEB is funded by NERC grant NE/D009197/1.

\section{References}

Anderson, G., et al. (2000), MODTRAN4: Radiative Transfer Modeling for Remote Sensing, in Algorithms for Multispectral, Hyperspectral, and Ultraspectral Imagery VI, edited by S. S. Chen and M. R. Descour, Proc. SPIE, 4049, 176-183.

Andreae, M., R. Charlson, F. Bruynseels, H. Storms, R. Van Grieken, and W. Maenhaut (1986), Internal mixtures of sea salt, silicates and excess sulfate in marine aerosols, Science, 232, 1620-1623, doi:10.1126/ science.232.4758.1620.

Bharmal, N., A. Slingo, G. Robinson, and J. Settle (2009), Simulation of surface and top of atmosphere thermal fluxes and radiances from the radiative atmospheric divergence using the ARM Mobile Facility, GERB data, and AMMA Stations experiment, J. Geophys. Res., 114, D00E07, doi:10.1029/2008JD010504.

Brindley, H. (2007), Estimating the top-of-atmosphere longwave radiative forcing due to Saharan dust from satellite observations over a west African surface site, Atmos. Sci. Lett., 8, 74-79, doi:10.1002/asl.155.

Brindley, H., and J. Russell (2006), Improving GERB scene identification using SEVIRI: Infrared dust detection strategy, Remote Sens. Environ., 104, 426-446, doi:10.1016/j.rse.2006.05.019.

Christopher, S., P. Gupta, J. Haywood, and G. Greed (2008), Aerosol optical thicknesses over North Africa: 1. Development of a product for model validation using Ozone Monitoring Instrument, Multiangle Imaging Spectroradiometer, and Aerosol Robotic Network, J. Geophys. Res., 113, D00C04, doi:10.1029/2007JD009446.

Clerbaux, N., S. Dewitte, L. Gonzalez, C. Bertrand, B. Nicula, and A. Ipe (2003), Outgoing longwave flux estimation: Improvement of angular modelling using spectral information, Remote Sens. Environ., 85, 389-395, doi:10.1016/S0034-4257(03)00015-4.

Clerbaux, N., J. Russell, S. Dewitte, C. Bertrand, D. Caprion, B. DePaepe, L. Sotelino, A. Ipe, R. Bantges, and H. Brindley (2009), Comparison of GERB instantaneous radiance and flux products with CERES Edition-2 data, Remote Sens. Environ., 113, 102-114, doi:10.1016/ j.rse.2008.08.016.

Derrien, M., and H. Le Gleau (2005), MSG/SEVIRI cloud mask and type from SAFNWC, Int. J. Remote Sens., 26, 4707-4732, doi:10.1080/ 01431160500166128.

Dewitte, S., L. Gonzalez, N. Clerbaux, A. Ipe, C. Bertrand, and B. DePaepe (2007), The geostationary earth radiation budget edition 1 data processing algorithms, Adv. Space Res., 41, 1906-1913, doi:10.1016/ j.asr.2007.07.042.

Diner, D., et al. (1998), Multi-angle Imaging SpectroRadiometer (MISR)Instrument description and experiment overview, IEEE Trans. Geosci. Eng., 36, 1072-1087, doi:10.1109/36.700992. 
Dunion, J., and C. Velden (2004), The impact of the Saharan air layer on Atlantic tropical cyclone activity, Bull. Am. Meteorol. Soc., 85, 353-365, doi:10.1175/BAMS-85-3-353.

Engelstaedter, S., I. Tegen, and R. Washington (2006), North African dust emissions and transport, Earth Sci. Rev., 79, 73-100, doi:10.1016/ j.earscirev.2006.06.004.

Fouquart, Y, B. Bonnel, G. Brogniez, J. Buriez, L. Smith, and J.-J. Morcrette (1987), Observations of Saharan aerosols: Results of ECLATS field experiment, part II, Broadband radiative characteristics of aerosols and vertical flux divergence, J. Clim. Appl. Meteorol., 26 , 38-52, doi:10.1175/1520-0450(1987)026<0038:OOSARO $>2.0$. CO;2.

Harries, J., et al. (2005), The Geostationary Earth Radiation Budget (GERB) project, Bull. Am. Meteorol. Soc., 86, 945-960, doi:10.1175 BAMS-86-7-945.

Haywood, J., R. Allan, I. Culverwell, A. Slingo, S. Milton, J. Edwards, and N. Clerbaux (2005), Can desert dust explain the outgoing longwave radiation anomaly over the Sahara during July 2003?, J. Geophys. Res., 110, D05105, doi:10.1029/2004JD005232.

Hess, M., P. Koepke, and I. Schult (1998), Optical properties of aerosols and clouds: The software package OPAC, Bull. Am. Meteorol. Soc., 79 831 - 844, doi:10.1175/1520-0477(1998)079<0831:OPOAAC $>2.0 . C O ; 2$.

Highwood, E., J. Haywood, M. Silverstone, S. Newman, and J. Taylor (2003), Radiative properties and direct effect of Saharan dust measured by the C-130 aircraft during Saharan Dust Experiment (SHADE): 2. Terrestrial spectrum, J. Geophys. Res., 108(D18), 8578, doi:10.1029/ 2002JD002552.

Holben, B., et al. (1998), AERONET-A federated instrument network and data archive for aerosol characterisation, Remote Sens. Environ., 66, 1-16, doi:10.1016/S0034-4257(98)00031-5.

Hsu, N., J. Herman, and C. Weaver (2000), Determination of radiative forcing of Saharan dust using combined TOMS and ERBE data, J. Geophys. Res., 105, 20,649-20,661, doi:10.1029/2000JD900150.

Ipé, A., C. Bertrand, N. Clerbaux, S. Dewitte, and L. Gonzalez (2004), Validation and homogenization of cloud optical depth and cloud fraction retrievals for GERB/SEVIRI scene identification using Meteosat-7 data, Atmos. Res., 72, 17-37, doi:10.1016/j.atmosres.2004.03.010.

Jiang, X., Y. Liu, B. Yu, and M. Jiang (2007), Comparison of MISR aerosol optical thickness with AERONET measurements in Beijing metropolitan area, Remote Sens. Environ., 107, 45-53, doi:10.1016/j.rse.2006.06.022.

Jickells, T., et al. (2005), Global iron connections between desert dust, ocean biogeochemistry, and climate, Science, 308, 67-71, doi:10.1126/ science. 1105959 .

Johnson, B., B. Heese, S. McFarlane, P. Chazette, A. Jones, and N. Bellouin (2008), Vertical distribution and radiative effects of mineral dust and biomass burning aerosol over west Africa during DABEX, J. Geophys. Res., 113, D00C12, doi:10.1029/2008JD009848.

Legrand, M., A. Plana-Fattori, and A. N'doumé (2001), Satellite detection of dust using the IR imagery of Meteosat: 1. Infrared difference dust index, J. Geophys. Res., 106, 18,251-18,274, doi:10.1029/ 2000JD900749.

Liu, D., A. Wang, Z. Liu, D. Winker, and C. Trepte (2008), A height resolved global view of dust aerosols from the first year of CALIPSO lidar measurements, J. Geophys. Res., 113, D16214, doi:10.1029/ 2007JD009776.

Martonchik, J., D. Diner, R. Kahn, B. Gaitley, and B. Holben (2004) Comparison of MISR and AERONET aerosol optical depths over desert sites, Geophys. Res. Lett., 31, L16102, doi:10.1029/2004GL019807.
MétéoFrance (2005), User manual for the PGE01-02-03 of the SAFNWC/MSG: Scientific part, Rep. SAF/NWC/IOP/MFL/SCI/SUM/ 01, 65 pp., Paris

Middleton, N., and A. Goudie (2001), Saharan dust: Sources and trajectories, Trans. Inst. Br. Geogr., 26, 165-181, doi:10.1111/14755661.00013

Offer, Z., and D. Goossens (2004), Thirteen years of Aeolian dust dynamics in a desert region (Negev desert, Israel): Analysis of horizontal and vertical dust flux, vertical dust distribution and dust grain size, J. Arid Environ., 57, 117-140, doi:10.1016/S0140-1963(03)00092-2.

Ridgwell, A. (2002), Dust in the Earth system: The biogeochemical linking of land, air and sea, Philos. Trans. R. Soc. London, 360, 2905-2924, doi:10.1098/rsta.2002.1096.

Satheesh, S., and K. Moorthy (2005), Radiative effects of natural aerosols: A review, Atmos. Environ., 39, 2089-2110, doi:10.1016/j.atmosenv. 2004.12.029.

Schepanski, K., I. Tegen, B. Laurent, B. Heinold, and A. Macke (2007), A new Saharan dust source activation frequency map derived from MSGSEVIRI IR-channels, Geophys. Res. Lett., 34, L18803, doi:10.1029/ 2007GL030168.

Schmetz, J., P. Pili, S. Tjemkes, D. Just, J. Kerkmann, S. Rota, and A. Ratier (2002), An introduction to Meteosat Second Generation (MSG), Bull. Am. Meteorol. Soc., 83, 977-992, doi:10.1175/15200477(2002)083<0977:AITMSG $>2.3$.CO 2 .

Slingo, A., et al. (2008), Overview of observations from the RADAGAST experiment in Niamey, Niger: Meteorology and thermodynamic variables, J. Geophys. Res., 113, D00E01, doi:10.1029/2008JD009909.

Smirnov, A., B. Holben, T. Eck, O. Dubovik, and I. Slutsker (2000), Cloud screening and quality control algorithms for the AERONET database, Remote Sens. Environ., 73, 337-349, doi:10.1016/S00344257(00)00109-7.

Tompkins, A., C. Cardinali, J.-J. Morcrette, and M. Rodwell (2005), Influence of aerosol climatology on forecasts of the African Easterly Jet, Geophys. Res. Lett., 32, L10801, doi:10.1029/2004GL022189.

Trigo, I., L. Peres, C. DaCamara, and S. Freitas (2008), Thermal land surface emissivity retrieved from SEVIRI/METEOSAT, IEEE Trans. Geosci. Remote Sens., 46, 307-315, doi:10.1109/TGRS.2007.905197.

Verge-Depre, G., M. Legrand, C. Moulin, A. Alias, and P. Francois (2006) Improvement of the detection of desert dust over the Sahel using Meteosat IR imagery, Ann. Geophys., 24, 2065-2073.

Volz, F. (1973), Infrared optical constants of ammonium sulphate, shara dust, volcanic pumice, and flyash, Appl. Opt., 12, 564-568, doi:10.1364/ AO.12.000564

Winker, D., W. Hunt, and M. McGill (2007), Initial performance assessment of CALIOP, Geophys. Res. Lett., 34, L19803, doi:10.1029/ 2007GL030135.

World Climate Program (1986), A Preliminary Cloudless Standard Atmosphere for Radiation Computation, World Meteorol. Org., Geneva.

Zhang, J., and S. Christopher (2003), Longwave forcing of Saharan dust aerosols estimated from MODIS, MISR, and CERES observations on Terra, Geophys. Res. Lett., 30(23), 2188, doi:10.1029/2003GL018479.

H. E. Brindley and J. E. Russell, Space and Atmospheric Physics Group, Blackett Laboratory, Imperial College London, London SW7 2AZ, UK. (h.brindley@imperial.ac.uk) 